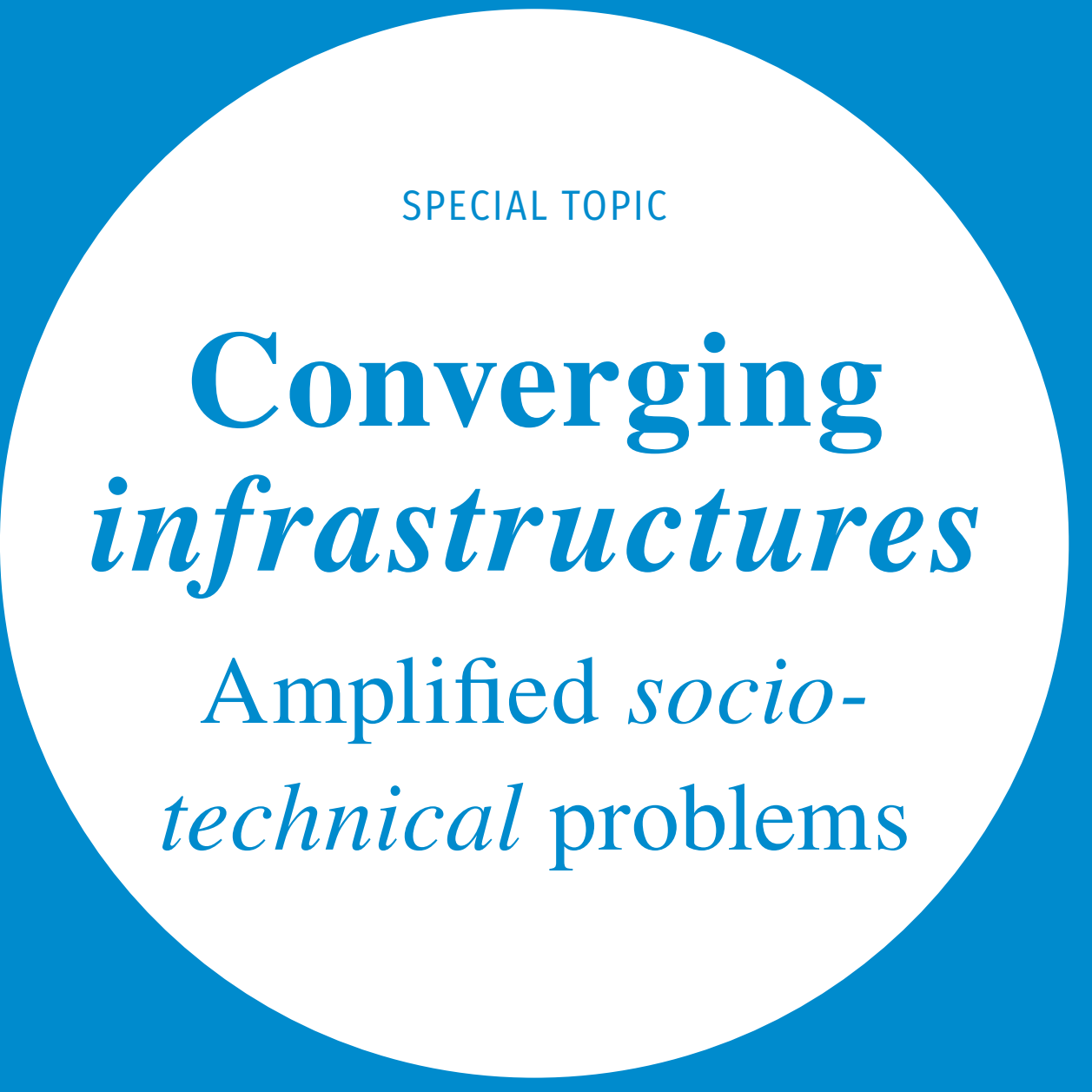

The term converging infrastructures illustrates the complexity of the processes involved in both operational sector coupling and socio-technical sector integration. What consequences of this development can already be estimated today and what difficulties will arise in doing so? A TATuP special topic edited by Christian Büscher, Michael Ornetzeder and Bert Droste-Franke. 


\title{
Amplified socio-technical problems in converging infrastructures
} A novel topic for technology assessment?

\author{
Christian Büscher, Institute for Technology Assessment and Systems Analysis (ITAS), Karlsruhe Institute of Technology (KIT), \\ Karlstr.11, 76133 Karlsruhe (christian.buescher@kit.edu) (D) https://orcid.org/0000-0002-8793-2438 \\ Michael Ornetzeder, Institute of Technology Assessment (ITA), Austrian Academy of Sciences (ÖAW) (michael.ornetzeder@oeaw.ac.at) \\ Bert Droste-Franke, IQIB - Institut für qualifizierende Innovationsforschung \& -beratung (bert.droste-franke@iqib.de)
}

Converging infrastructures illustrate the complexity of the processes involved in both operational sector coupling and socio-technical sector integration. What consequences of this development can technology impact research estimate today and what difficulties will arise in doing so? This article introduces the TATuP special topic as well as the individual contributions and also addresses socio-political aspects, beyond the usual questions of technical feasibility and efficiency: What strategies are developed to initiate and control comprehensive change? What are the mechanisms to maintain the ability to act despite great uncertainties for all those concerned with future converging infrastructures for energy, transport, and heating/cooling. The interdisciplinary approach to the topic focuses on three central "socio-technical problems" and gives a first insight into the conditions under which converging infrastructures emerge and what consequences these processes might have.

\section{Die Verschärfung sozio-technischer Probleme in konvergierenden Infrastrukturen}

Ein neues Thema für die Technikfolgenabschätzung?

Konvergierende Infrastrukturen verdeutlichen die Komplexität in Prozessen der operationalen Sektorkopplung sowie der soziotechnischen Sektorintegration. Welche Konsequenzen dieser Entwicklung kann die Technikfolgenforschung bereits jetzt abschätzen und welche Schwierigkeiten ergeben sich dabei? Dieser Artikel stellt das TATuP-Thema sowie die einzelnen Beiträge vor und stellt neben technischer Machbarkeit und Effizienz auch explorative Fragen nach gesellschaftspolitischen Aspekten: Welche Strategien sollen den umfassenden Wandel initiieren und kontrollieren? Welche Mechanismen erlauben Handlungsfähigkeit trotz großer Unsicherheiten für zukünftige Akteure konvergierender In-

This is an article distributed under the terms of the Creative Commons Attribution License CCBY 4.0 (https://creativecommons.org/licenses/by/4.0/)

https://doi.org/10.14512/tatup.29.2.11 frastrukturen für Energie, Transport und Wärme/Kühlung? Der interdisziplinäre Ansatz orientiert sich an drei zentralen „soziotechnischen Problemen " und gibt einen ersten Einblick, unter welchen Bedingungen konvergierende Infrastrukturen entstehen und welche Konsequenzen diese Prozesse möglicherweise haben werden.

Keywords: sector coupling and integration, energy and transport, complexity and control, change and stability, action under uncertainty

\section{The convergence of infrastructures: promise or paradigm?}

The coupling of infrastructure sectors such as energy and transport or heating and cooling is becoming an important topic in energy transition studies. Sector coupling may not only lead to an overall more efficient use of energy but also make a substantial contribution to the more widespread use of renewable energy sources (RES). Scholars and practitioners approach the topic from very different perspectives and with different goals. There are, for example, publications on scenario-building and meta-studies (Ausfelder et al. 2017), modeling (Robinius et al. 2017 a, 2017b), case studies and visions (Canzler and Knie 2013), economic reports (acatech et al. 2018), governance research (Hoffrichter and Beckers 2018), and stakeholder analyses (Bauknecht et al. 2018). However, the question remains whether sector coupling is still in the stage of an expectation statement, i. e., the explication of a vision, an emerging technology, or a "promising technology" (van Lente 2000, p. 60), or whether we are actually witnessing the consolidation of a scientific, economic, or political agenda (Bender 2005). Proponents of this approach no longer discuss sector coupling only as a promise to 
increase resource use efficiency and an opportunity to reduce greenhouse gas emissions, but agree in unison that it is an essential requirement for slowing down climate change. However, sector coupling goes far beyond the technical coupling of production and consumption systems. The success of technical sector coupling depends on socio-technical sector integration through consideration and combination of multiple types of knowledge, the creation of new social networks, the alignment of technical norms and standards, and new forms of social coordination in markets and in regulation between actors and sectors. For this reason, we propose the term "converging infrastructures", which ultimately implies the interlinking and transformation of existing socio-technical systems. Converging infrastructures illustrate the complexity of the processes involved in both operational sector coupling and socio-technical sector integration.

There is evidence suggesting that integrated approaches will become increasingly important in the coming years, not only in research but also through the implementation of political measures or the realization of infrastructure projects. Against this background, some important questions arise:

- To what extent is it possible to combine previously separate infrastructures into integrated entities in the future?

- What social and technical implications and risks would such far-reaching changes entail?

- Finally, how could the emerging complexity be adequately investigated and how should possible consequences be addressed?

This TATuP special topic aims to provide some preliminary considerations on converging infrastructures and thus provide a stimulus to further explore the possibilities and consequences of this development from the perspective of different disciplines. Therefore, we propose the concept of socio-technical problems as a heuristic to gain insights from various disciplinary perspectives. This concept was initially developed to identify common reference problems in interdisciplinary energy research. ${ }^{1}$ The underlying idea was to support a cognitive integration of various contributions without burdening the collaborative work with excessive discussions on the identification of shared research objects (Büscher et al. 2018).

\section{What are socio-technical problems?}

Many scholars in the field of energy transitions emphasize the need to consider technical systems, organizations, regimes or networks, as well as individual and collective action affecting system operations (Geels 2004; Bolton and Foxon 2015; Cherp

1 The concept started to take shape in the Helmholtz Alliance ENERGY-TRANS (2011-2016), which consisted of an interdisciplinary group of about 80 researchers from different disciplinary backgrounds who investigated the interactions between technical and societal developments in the context of the German energy transition (www.energy-trans.de) et al. 2018). Terms such as socio-technical systems, actor networks, or social practices are used to emphasize the close interrelation between technical artifacts or operations, on the one hand, and social behavior, action, or decision making, i. e., communication, on the other. We assume that the topic of sector coupling needs to be addressed in a similar way - in reference to technical and social elements.

Furthermore, researchers argue that system transitions are triggered if societal functions are at risk, since unsustainable consumption of fossil fuels endangers energy supply and promotes climate change. Grin et al. (2010, pp. 2) argue that "persistent problems" deeply embedded in the structure of social systems result in innovative practices and structural adaptation, which eventually lead to system innovation and transitions as a possible response to these problems. However, the ever increasing complexity of energy supply observed in recent years produces a growing variety of solutions to existing problems, and these "solutions" almost simultaneously lead to new problems (Schuitmaker 2012, p. 1023). We only have to consider how the introduction and implementation of RES during the last decades has partly replaced fossil energy supply and brought about new challenges for storage and transport (e. g., of electricity), for the organization of production (market interaction, regulation), or for legislative decision making regarding the installation of corresponding infrastructures (power plants, physical networks).

The historian Paul Edwards, who sees large infrastructures not only as solutions to societal problems but also as a constant challenge, argues in the same direction: "The overall [socio-technical] system can be fruitfully described as posing a linked series of socio-technical problems" (Edwards 2004, p. 209). He thus refers to problems that cannot be reduced to either technical or social characteristics, that cannot be solved for good, i. e., definitively, and that need to be addressed constantly, i. e., today, tomorrow, next year, and, if we think about sustainability, for the next centuries.

Existing research from science and technology studies (STS), large technical systems theory (LTS), systems theory, transition and innovation research, etc. offers a rich body of literature that helped to identify core issues and thus to reformulate them as the following socio-technical problems (Büscher et al. 2018):

- The factual dimension refers to the issue of the increasingly complex interaction between technical and social elements, such as physical installations and networks with social organization, and the ensuing quest for maintaining control, e.g., in terms of predictability, security, safety, efficiency, etc. (problem of control).

- The social dimension focuses on generally shared expectations, i. e., institutions, where the different participants involved in the provision and use of services (actors, parties, persons, agents, stakeholders, organizations, etc.) find mutual orientation, and where change is enacted upon or by the activities of all parties involved (problem of change). 
- The temporal dimension stresses the need to act in the present, despite the past serving only as experience and the future not yet being known, as well as the problem of coping with uncertainty and risk. This dimension is particularly affected by the consequences of energy transitions, because the resulting structural complexity and institutional change increase non-transparency and challenge the ability to act and take decisions (problem of action).

All three problem dimensions represent, in an abstract way, challenges for the energy complex as a whole as well as for the ongoing energy transition. These dimensions serve as an analytical heuristic; they are simultaneously effective and influence each other, as will be discussed in more detail below.

\section{Control despite complexity}

The problem of energy supply is addressed through a heterogeneous structure of a comprehensive energy complex comprising several technical and organizational systems and subsystems. The notion of structure refers to a chain of technical and social events that at best produces the expected output (Hughes 1983, p. 5). System structures aim to enable control of technical operation and social activities as well as the interaction of both, in particular to align the actual behavior of a system with its intended behavior (Nightingale et al. 2003, p. 484). In this sense, technology is always operated within the medium of instrumentality and under conditions of limited operating principles (conservation, transformation, storage, and transmission) (Beckman 1994, p. 320). In complicated technical systems, all of these principles come into effect simultaneously, and thus technology represents the determination of production and demand (of services and goods).

In the early stages of the development of power grids, control was the major problem if further rationalization and optimization was to be realized (Hughes 1983, p.367). In order to achieve economically effective operation, operators had to align physical structures and machine operation with increasingly sophisticated means of social organization in order to manipulate the "load factor" (the ratio of actual energy output to the theoretical maximum output of a power plant) of the system. In the search for the most economically effective system architecture, system traffic must be allocated. Capacity utilization changes from moment to moment, as does the internal state, the load factor, which must be continuously optimized. Consequently, social settings are required to safeguard critical functions: the organization of operation monitoring (metering, comparing, compensating, actuating), the coordination of activities; the restriction of access to the system or network; the starting-up or shutting-down of facilities connected to the overall system (Künneke et al. 2010, p. 499).

These challenges, as we assume, have become more acute in recent decades with the introduction and dissemination of RES, energy storage options, and new market models (Droste-Franke et al. 2012). We must assume that the problem of control will intensify with recent developments of sector integration.

\section{Change despite stability}

Sustaining functions while simultaneously enabling change refers to the problem of balancing redundancy and variety (Atlan 1974, p. 300). The transition from one system to another (or the transformation of a system during operation) implies changes while society still depends on the output and services of the system. Structural changes affect the way social actors orient themselves mutually in the complexity of the energy system. Users expect energy services that are reliable, safe, and affordable, and this expectation is deeply entrenched in the industrialized world. The major changes that began in the nineteenth century - the shift from a biomass-based to a fossil fuel-based economy and the diversification of energy sources (Fouquet 2016) - led to industrial society's dependence on the exponential exploitation of energy sources such as coal, oil, or gas (Hagens 2020, p. 5). Since then, energy infrastructures have been operated in a highly redundant mode - reliably providing energy through refineries and pipelines as well as large power plants and vast networks. The transformation of energy systems worldwide will change this situation. After decades of successful deployment of conventional means of energy supply, the contingency of such paradigms has been revealed through the increasing use of renewable energy sources, decentralized network architectures, and novel business models (including, for example, small municipal cooperatives).

However, transformations that vary greatly in their degree, scope, and pace result in high complexity (Gallagher et al. 2012, p. 144). Stable orientation may get lost and the self-organizing capacities of social systems are at stake (Atlan 1974, p. 300). Both variety and redundancy are essential, but too much variety leads to volatile, erratic behavior, whilst too much redundancy causes inertia, lock-ins, and path dependencies (which in turn maintain redundancy).

In our case, it is interesting to look into the possible drivers (derived from research on energy transitions) of sector integration. These may be technical and social innovations that challenge established regimes (Geels 2014); energy and climate policy initiatives that aim to transform existing systems (Cherp et al. 2018); synchronized development processes designed to involve actors at all relevant levels, e. g., in the area of knowledge acquisition and exchange; processes of behavioral change as part of innovation processes, i. e., "exnovation" of established practices and commonly shared knowledge (David and Gross 2019); changes and events in the external landscape that also put pressure on the regimes (e.g., technical accidents and effects of climate change, as well as global recessions and pandemics).

\section{Action(ability) despite non-transparency}

In converging infrastructures we will encounter many physical, digital, and social relationships between systems (e. g., power plants, vehicles, manufacturing facilities), networks of systems (e. g., smart grids), and networks of networks (e. g., Internet of Everything), as well as between diverse social actors such as operators and designers, legislators, controllers, electricity suppli- 
ers, and customers and many more. In these socio-technical constellations, many of the emerging relationships take the form of "flat" screens for the user interface, as opposed to the "deep" and complicated structure of the system behind the surface. This increases the experience of non-transparency of relevant operations and thus of uncertainty and risk (Büscher 2018, p. $26 \mathrm{ff}$.).

Within socio-technical constellations, operators are responsible for maintaining control from moment to moment, taking account of planned changes toward the convergence of infrastructures. The modeling of possible failures and threats in order to address vulnerabilities or increase resilience is a serious challenge (Kröger and Nan 2018). Lack of data hampers informed decision making. Uncertainty must be absorbed by distributing risks and responsibilities, legal protection, and informal mechanisms such as trust and confidence. In situations of change, plausible decision-making programs replace accurate calculations for decision making (Weick et al. 2005, p. 415). In practice, the problem of coping with uncertainty exists, for example, with respect to interconnected infrastructures (Roe and Schulman 2016, p. 62). In order to ensure reliable operation even beyond the planned and intended design, engineers, policy makers, or managers, must trust in the skills and knowledge of the practitioners operating the facilities from moment to moment (Roe and Schulman 2016, p. 156).

In addition, visions of smart grids and novel markets propose a bi-directional data exchange between providers and consumers. Especially consumers are expected to be involved more actively in both the production and consumption of electricity. The term prosumer clearly indicates these changes on the supply side. The industry is searching for viable business cases and models for smart appliances and prosumer roles, as already seen in "virtual power plants" (Dürr and Heyne 2017), while politicians, administrators, and consumer protection associations are looking for ways to enable innovation and protection of prosumers at the same time (Covrig et al. 2014, p. 87). Moreover, the problem of lack of insight into the behavior, e. g., the algorithms, of smart technology may progressively become the most important issue for all parties involved (Milchram et al. 2018, p. 11).

\section{Contributions}

It is well recognized that sector integration is of considerable importance to the transition of the energy system toward decarbonization goals. And it is very likely that its importance will increase in the coming years. However, the benefits of this approach face a number of critical challenges. The underlying rationale for this TATuP special topic is the legitimate assumption that converging infrastructures, i. e., the operational coupling and social, organizational, and institutional integration of sectors, will significantly increase socio-technical problems, as briefly sketched above. Socio-technical entities, which incorporate a large number of heterogeneous elements and interrelationships, already today impose a high degree of complexity on op- erators, supervisors, and users and will most likely become even more complex in the future. As a result, the effort required for controlling and governing these systems - both their operation and transition - will increase significantly. New risks and side effects will certainly arise that are difficult to predict. One way to deal with this situation is to address the resulting socio-technical problems in their factual, social, and temporal dimension. The contributions to this special topic refer to these dimensions and the associated dilemmas in a number of ways. In this sense, the contributions in this volume further explore, test, and deepen the concept of converging infrastructures from various disciplinary perspectives:

In their contribution, Christian Büscher, Dirk Scheer, and Lisa Nabitz take up the challenge of reviewing existing knowledge about sector coupling and its various implications. They do so by drawing on the concept of socio-technical problems, which should make it possible to better portray the manifold consequences and risks of integrating several sectors and forms of energy. They note that sector coupling is widely seen as a promising strategy to increase resource and energy efficiency and, thus, to reduce greenhouse gas emissions, but that it is typically accompanied by greater technical and social diversity. This increases, among other things, the complexity of existing systems, entails uncertainties and risks, and increases the need for coordination between various actors. A number of studies claim that politics has a central role to play as initiator and facilitator of the intended infrastructural changes. Although the associated political risks are known, there is a lack of analyses of possible strategies to deal with such risks. The review also shows, however, that there are hardly any studies that deal with the risks and uncertainties associated with the operation of integrated infrastructures. The authors conclude that future research should address issues such as exnovation, the coordination of key innovation actors, or the role of multi-level governance systems in more detail to better reflect the socio-technical nature of converging infrastructures.

Oberle at al. present an analysis of options for residential heating, which shows the relevance of sector coupling and the need for active coordination of the transformation processes in this area. They start with the characterization of the three competing infrastructures gas networks, heating networks, and electricity grids as well as the respective options for installed heating devices. Based on current conditions and a projection for 2050, an aggregated assessment of all costs and $\mathrm{CO}_{2}$ emissions of the currently most relevant and promising variants of gas condensing boilers, heat pumps, and connections to a heating network is carried out. With natural gas and synthetic methane, two options for gaseous fuels are considered. The resulting cost estimates show large differences and reveal that sector coupling needs to be taken into account in future infrastructure planning. In designing infrastructures during the transformation process, such analyses need to be considered, but be complemented by more in-depth research and against the background of socio-technical systems with wider consideration of disciplinary aspects, options, impacts, and framework conditions. 
The case of the Dutch energy transition strengthens the argument of continuous socio-technical problems. In order to achieve the ambitious decarbonization policy objectives, as Romi Dekker and Rinie van Est claim, Dutch policy focuses primarily on technical solutions, i. e., renewable energy sources. The dissemination of RES brings about many new problems. In this case, the need for "smarter" control of a decentralized, distributed energy complex in conjunction with electrified transport and heating. The core believe of Dutch policy is "digitalization" (besides liberalization and privatization), because only information and communication technology promises to help secure reliable, efficient, affordable, and inclusive services. Dekker and van Est emphasize in this context that digitalization is becoming an integral part of any political agenda in response to increasing complexity (from promise to requirement). However, it is precisely the means of mitigating the problem of complexity that contributes to this situation: "On the other hand, since they increase the diversity of actors and add new roles, smart grids also add extra complexity with regard to organizing the electricity market" (Dekker and van Est in this issue, p. 34). In the future, topics such as digital security, data governance, equality, and justice in the distribution of costs and benefits as well as a (presumably government-led and observed by non-governmental actors) supervision of digitalization will become pressing issues for academic research (especially TA), policy making, and public debate.

Michael Ornetzeder and Tanja Sinozic present an example of a pilot project in which several novel technologies are tested in an actively designed niche situation. The case study is about a smart energy housing project in Austria, in which the heating, gas, and electricity sectors were interlinked in several ways. They show that sector coupling in this case was substantially supported by niche protection activities, which enabled the development of a comprehensive actor network structure, and by long-established cognitive and organizational routines. Among other things, it seemed to be crucial for the implementation of the pilot project that the main project owner had a long history as a multi-utility company and that services and infrastructure units were never completely unbundled in the course of the liberalization of the energy markets. This constellation enabled an effective management of potential technical, economic, and organizational risks. The example also shows that end users are not entirely satisfied with the monopoly-like situation resulting from the arrangement applied. Furthermore, the project setting and the design of the follow-up projects implemented under current market conditions show that the economic and legal framework conditions still need to change in order to realize the full potential of sector coupling.

Finally, Bert Droste-Franke presents the manifold perils and challenges for the theory and practice of systems analysis in the case of converging infrastructures. Droste-Franke emphasizes that the basic socio-technical problems outlined above also apply to systems analysis and corresponding scientific modeling efforts. The approach becomes self-reflexive. Looking at the sci- ence-policy interface, Droste-Franke raises questions about the quality of models and the underlying presumptions and premises in relation to, first, the research object of interest, i. e., the complex of operating and simultaneously transforming systems, and, second, in relation to the need for system knowledge. The latter refers to the attempt to clarify the conditions for providing sound advice that is instructive for different actors in different situations. For the topic of converging infrastructures, the problem of controlling all relevant elements and their interrelations in the modeling process becomes prevalent. Predicting the innovation dynamics resulting from a myriad of micro processes compared to past developments also becomes a challenge. Consequently, also modeling methods must be altered to take account of multiple disciplinary insights and expose constant patterns in innovation dynamics (redundancy in a stream of varying events). Coping with uncertainty in modeling is therefore an inherent feature of this work. Also, finding the means to communicate scientific uncertainty to those seeking advice is crucial. The mode of communication seems decisive to foster some confidence in scientific expertise. Only then can decision makers on the future course of sector integration be put in a position to act based on the information provided.

\section{References}

acatech et al. - National Academy of Science and Engineering, acatech; German National Academy of Sciences, Leopoldina; Union of the German Academies of Sciences and Humanities, Akademieunion (2018): Coupling the different energy sectors. Options for the next phase of the energy transition. Berlin: Königsdruck.

Atlan, Henry (1974): On a formal definition of organization. In: Journal of Theoretical Biology 45 (2), pp. 295-304.

Ausfelder, Florian et al. (2017): Sektorkopplung. Untersuchungen und Überlegungen zur Entwicklung eines integrierten Energiesystems (Schriftenreihe Energiesysteme der Zukunft). Berlin: Königsdruck.

Bauknecht, Dierk et al. (2018): Visionen und Pfadentscheidungen der Energiewende. Freiburg: Öko-Institut e.V.

Beckman, Svante (1994): On systemic technology. In: Jane Summerton (ed.): Changing large technical systems. Boulder: Westview Press, pp.311-331. Bender, Gerd (2005): Technologieentwicklung als Institutionalisierungsprozess. In: Zeitschrift für Soziologie 34 (3), pp. 170-186.

Bolton, Ronan; Foxon, Timothy (2015): Infrastructure transformation as a sociotechnical process. Implications for the governance of energy distribution networks in the UK. In: Technological Forecasting and Social Change 90, Part B, pp. 538-550. DOI: 10.1016/j.techfore.2014.02.017.

Büscher, Christian (2018): Framing energy as a sociotechnical problem of control, change, and action. In: Christian Büscher, Jens Schippl and Patrick Sumpf (eds.): Energy as a sociotechnical problem. An interdisciplinary perspective on control, change, and action in energy transitions. London: Routledge, pp. 14-38.

Büscher, Christian; Schippl, Jens; Sumpf, Patrick (eds.) (2018): Energy as a sociotechnical problem. An interdisciplinary perspective on control, change, and action in energy transitions. London: Routledge.

Canzler, Weert; Knie, Andreas (2013): Schlaue Netze. Wie die Energie- und Verkehrswende gelingt. Munich: Oekom. 
Cherp, Aleh; Vinichenko, Vadim; Jewell, Jessica; Brutschin, Elina; Sovacool, Benjamin (2018): Integrating techno-economic, socio-technical and political perspectives on national energy transitions: A meta-theoretical framework. In: Energy Research \& Social Science 37, pp. 175-190. DOI: 10.1016/j.erss.2017.09.015.

Covrig, Catalin; Ardelean, Mircea; Vasiljevska, Julja; Mengolini, Anna; Fulli, Gianluca; Amoiralis, Eleftherios (2014): Smart grid projects outlook 2014. Luxembourg: Publications Office of the European Union.

David, Martin; Gross, Matthias (2019): Futurizing politics and the sustainability of real-world experiments. What role for innovation and exnovation in the German energy transition? In: Sustainability Science 14 (4), pp. 991-1000.

Droste-Franke, Bert et al. (eds.) (2012): Balancing renewable electricity. Energy storage, demand side management, and network extension from an interdisciplinary perspective. Berlin: Springer.

Dürr, Thomas; Heyne, Jean-Christoph (2017): Virtuelle Kraftwerke für Smart Markets. In: Oliver Doleski (ed.): Herausforderung Utility 4.0. Wie sich die Energiewirtschaft im Zeitalter der Digitalisierung verändert. Wiesbaden: Springer Vieweg, pp. 653-681.

Edwards, Paul (2004): Infrastructure and modernity. Force, time, and social organization in the history of socio-technical systems. In: Thomas Misa, Philip Brey and Andrew Feenberg (eds.): Modernity and technology. Cambridge: MIT Press, pp. 185-225.

Fouquet, Roger (2016): Historical energy transitions. Speed, prices and system transformation. In: Energy Research \& Social Science 22, pp.7-12.

Gallagher, Kelly; Grübler, Arnulf; Kuhl, Laura; Nemet, Gregory; Wilson, Charlie (2012): The energy technology innovation system. In: Annual Review of Environment and Resources 37 (1), pp. 137-162. DOI: 10.1146/annurevenviron-060311-133915.

Geels, Frank (2004): From sectoral systems of innovation to socio-technical systems. Insights about dynamics and change from sociology and institutional theory. In: Research Policy 33 (6-7), pp. 897-920.

Geels, Frank (2014): The arduous transition to low-carbon energy. A multi-level analysis of renewable electricity niches and resilient regimes. In: Jan Fagerberg, Steffan Laestadius and Ben Martin (eds.): The triple challenge for Europe. Economic development, climate change, and governance. Oxford: Oxford University Press, pp. 91-118.

Grin, John; Rotmans, Jan; Schot, Johan (2010): Transitions to sustainable development. New directions in the study of long term transformative change. New York: Routledge.

Hagens, Nathan (2020): Economics for the future. Beyond the superorganism. In: Ecological Economics 169, p. 16. DOI: 10.1016/j.ecolecon.2019.106520.

Hoffrichter, Albert; Beckers, Thorsten (2018): Cross-border coordination as a prerequisite for efficient sector coupling in interconnected power systems. Institutional economic considerations on allocating decision-making competencies in the European Union. Berlin: Technische Universität Berlin.

Hughes, Thomas (1983): Networks of power. Electrification in Western society, 1880-1930. Baltimore: The Johns Hopkins University Press.

Kröger, Wolfgang; Nan, Cen (2018): Power systems in transition. Dealing with complexity. In: Christian Büscher, Jens Schippl and Patrick Sumpf (eds.): Energy as a sociotechnical problem. An interdisciplinary perspective on control, change, and action in energy transitions. London: Routledge, pp. 41-78.

Künneke, Rolf; Groenewegen, John; Ménard, Claude (2010): Aligning modes of organization with technology. Critical transactions in the reform of infrastructures. In: Journal of Economic Behavior \& Organization 75 (3), pp. 494-505.

Milchram, Christine; Hillerbrand, Rafaela; van de Kaa, Geerten; Doorn, Neelke; Kunneke, Rolf (2018): Energy justice and smart grid systems. Evidence from the Netherlands and the United Kingdom. In: Applied Energy 229, pp. 1244-1259. DOI: 10.1016/j.apenergy.2018.08.053.

Nightingale, Paul; Brady, Tim; Davies, Andrew; Hall, Jeremy (2003): Capacity utilization revisited. Software, control and the growth of large technical systems. In: Industrial and Corporate Change 12 (3), pp. 477-517.

Robinius, Martin et al. (2017 a): Linking the power and transport sectors. Part 1: Modelling a sector coupling scenario for Germany. In: Energies 10 (7), p. 22. DOI: 10.3390/en10070956

Robinius, Martin et al. (2017 b): Linking the power and transport sectors. Part 2: Modelling a sector coupling scenario for Germany. In: Energies 10 (7), p. 23. DOI: $10.3390 /$ en10070957.

Roe, Emery; Schulman, Paul (2016): Reliability and risk. The challenge of managing interconnected infrastructures. Stanford: Stanford University Press.

Schuitmaker, Tjerk (2012): Identifying and unravelling persistent problems. In: Technological Forecasting and Social Change 79 (6), pp.1021-1031.

van Lente, Harro (2000): Forceful futures. From promise to requirement. In: Nik Brown, Brian Rappert and Andrew Webster (eds.): Contested futures. A sociology of prospective techno-science. Aldershot: Ashgate, pp. 43-63. Weick, Karl; Sutcliffe, Kathleen; Obstfeld, David (2005): Organizing and the process of sensemaking. In: Organization Science 16 (4), pp. 409-421.

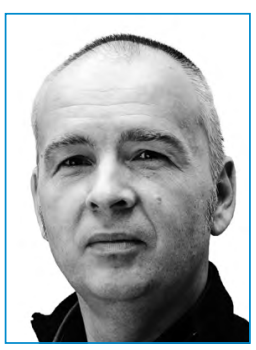

\section{DR. CHRISTIAN BÜSCHER}

is since 2006 member of scientific staff at the Institute for Technology Assessment and Systems Analysis (ITAS). His research topics cover the theoretical embedment of technology assessment, social science-based energy research and risk and ecological sociology.

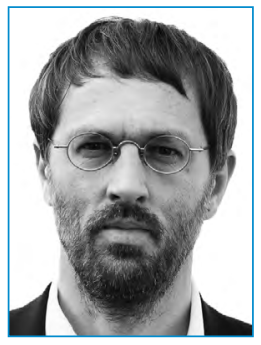

PRIV.-DOZ.MAG.DR. MICHAEL ORNETZEDER

is a Senior Researcher at the Institute of Technology Assessment (ITA), Austrian Academy of Sciences. He has PhD and post-doc level research and teaching experience in technology assessment and science and technology studies, with a particular focus on energy transitions, sustainable energy technologies, user innovation, and social learning.

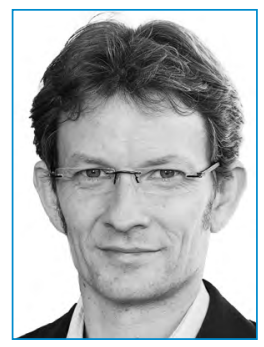

\section{DR. BERT DROSTE-FRANKE}

is head of research at IQIB. His research interests are systems analyses, innovation analyses and technology assessment for policy advice, based on theoretical work, inter- and trans-disciplinary expert groups, quantitative analyses and modelling. 


\title{
Future converging infrastructures
}

\author{
Assessing the consequences of increasing \\ sector coupling and integration
}

\begin{abstract}
Christian Büscher, Institute for Technology Assessment and Systems Analysis (ITAS), Karlsruhe Institute of Technology (KIT), Karlstr.11, 76133 Karlsruhe (christian.buescher@kit.edu) (1) https://orcid.org/0000-0002-8793-2438

Dirk Scheer, Institute for Technology Assessment and Systems Analysis (ITAS), Karlsruhe Institute of Technology (KIT) (dirk.scheer@kit.edu) (1) https://orcid.org/0000-0002-7472-8331
\end{abstract}

Lisa Nabitz, Institute for Technology Assessment and Systems Analysis (ITAS), Karlsruhe Institute of Technology (KIT) (lisa.nabitz@kit.edu)

The process of converging infrastructures - the integration and coupling of the energy, transport, heating and cooling sectors - challenges technological paradigms and economic structures as well as patterns of individual and collective action. Renewable energy sources (RES), physical and digital networks, and new market opportunities promise more efficient use of energy and reduced emissions. However, every technological solution creates new problems. Therefore, we propose to analyze possible developments by exposing socio-technical problems. This contribution analyses recent studies drawing on sector coupling and assesses the consequences of converging infrastructures.

\section{Zukünftige konvergierende Infrastrukturen}

Bewertung der Folgen einer zunehmenden Sektorkopplung

Der Prozess konvergierender Infrastrukturen - die Integration und Kopplung der Sektoren Energie, Transport und Wärme bzw. Kühlung fordert technologische Paradigmen und Wirtschaftsstrukturen heraus, ebenso wie Muster individuellen und kollektiven Handelns. Erneuerbare Energiequellen, physikalische und digitale Netze sowie neue Marktchancen versprechen einen effizienteren Umgang mit Ressourcen und eine Reduzierung von Emissionen. Jede neue Technologie erzeugt aber nicht nur Lösungen, sondern auch neue Probleme. Deshalb schlagen wir vor, mögliche Entwicklungen anhand exponierter "soziotechnischer Probleme" zu untersuchen. Dieser Beitrag analysiert aktuelle Studien zur Sektorkopplung und bewertet die Folgen der Konvergenz von Infrastrukturen.

Keywords: complexity, control, socio-technical change, decision making, uncertainty

This is an article distributed under the terms of the Creative Commons Attribution License CCBY 4.0 (https://creativecommons.org/licenses/by/4.0/)

https://doi.org/10.14512/tatup.29.2.17

Submitted: 20.02.2020. Peer reviewed. Accepted: 15. 05.2020

\section{Introduction}

Basic services in modern society - energy supply, transport, heating and cooling - need to be maintained, despite numerous problems such as continuous $\mathrm{CO}_{2}$ emissions, resource scarcity, or dangerous technologies and hazardous waste. Experts call for a holistic transformation of societies' vital infrastructures in order to eliminate, or at least mitigate, these undesirable side effects. To achieve significant reductions in greenhouse gas emissions, the transformation of individual sectors as well as tighter operational coupling and organizational integration of technical and social systems is required (Robinius et al. 2017 a, p. 2 ff.).

In Germany, the idea of sector coupling has become a prominent strategy to meet these objectives. With several emerging technologies enabling sector coupling (including developments in renewable energy sources [RES], heat pumps, combined heat and power [CHP] systems, synthetic fuel production, electric cars, or developments in information and communication technologies), researchers propose different sector coupling pathways that combine research and development activities and energy-related practices. In a broad understanding, the idea of sector coupling refers to the integration of energy systems with the "process of coordinating the operation and planning of energy systems across multiple pathways and/or geographical scales to deliver reliable, cost-effective energy services with minimal impact on the environment" (O'Malley and Kroposki 2017, p. 10).

This vision entails - as we understand it - a process of converging infrastructures that results in the design and implementation of

1. tighter coupling of operations of conservation, conversion, storage, and/or transmission of energy (Beckman 1994, p. 321) in order to impose control of the allocation of systemwide operations (Nightingale et al. 2003), and 
2. tighter organizational and institutional integration to harmonize the interaction of different actors with different purposes, such as design and engineering, supervision, investment, and/ or consumption of services (Franssen and Kroes 2009).

This contribution is concerned with the assessment of possible consequences of converging infrastructures related to sector coupling strategies. We refer to the notion of "socio-technical problems" (Edwards 2004, p. 209) to expose issues that usually receive less attention in engineering or economic modeling, but to which social science research and technology assessment can contribute with complementary perspectives.

Existing research from the fields of science, technology and society studies (STS), large technical systems theory (LTS), systems theory, or transition and innovation research, offers a rich body of literature to (tentatively) extract and differentiate the key issues and reduce them to core socio-technical problems. From a factual point of view, with converging infrastructures, we must assume increasingly complex interactions between technical and social elements, such as physical installations and networks with social organization, and the ensuing quest for maintaining control, e.g., in terms of predictability, security, safety, and efficiency. From a social perspective, the problem of generally shared expectations comes into focus, i. e., institutions where different actors, parties, persons, agents, or stakeholders must find mutual orientation in a converging field, such as energy, transport, and heating/cooling, and where change is enacted upon or by the activities of all parties involved. From a temporal point of view, the problem of coping with uncertainty and risk stresses the need to act in the present, despite the past serving "only" as experience and the future being not yet determined. In this dimension, the consequences of energy transitions are particularly evident, because the resulting structural complex-

Sector coupling will integrate

\section{energy infrastructure in areas that \\ have so far operated side by side.}

ity and institutional change increase non-transparency and challenge the ability to act. All three dimensions represent the socio-technical reality of converging entities and, subsequently, influence each other. The concept of socio-technical problems is laid out in detail in Büscher (2018) and serves as a heuristic to structure possible issues of integration processes (see also the introduction to this TATuP special topic by Christian Büscher, Michael Ornetzeder, and Bert Droste-Franke).

To begin with, we selected recent sector coupling studies for Germany as a data set (acatech et al. 2018; Ausfelder et al. 2017; Bauknecht et al. 2018; Henning and Palzer 2015; Hoffrichter and Beckers 2018; Wietschel et al. 2018; Winter 2018). Almost all of them are studies based on publicly funded projects and claim to provide orientation and advice to policy makers. We therefore assume that these studies have an influence on policy and decision makers in choosing and designing future pathways to integration and coupling of infrastructures. The basic observation is that sector coupling will integrate energy infrastructure (e.g., technical, social, and institutional) in areas that have so far operated largely side by side. In order to explore the consequences of future converging infrastructures, we will direct the following questions to the selected studies and try to identify proposed solutions and remaining issues:

1. With converging infrastructures, we can assume that more and more technical systems and social actors will be intertwined. Consequently, we must ask how the problem of control for secure, reliable, cost-effective, and sustainable operation of the energy system can be solved despite increased socio-technical complexity. What are the technical and organizational means to achieve sector coupling?

2. Change must be enacted in various sectors simultaneously, despite the need for continued reliable operation and secure services. The question arises how and by whom technical and social innovation processes are initiated. Is the public administration, the private sector, or the public at large the driver of sector coupling?

3. Uncertainty must be absorbed in order to maintain the ability to act in the transformation of various sectors. In the face of complicated technologies and complex transformations, social mechanisms must be in effect to enable decision making and action despite increasing non-transparency. Therefore, we need to ask what problems and strategies for coping with uncertainties we can find in our set of studies.

The literature we subsequently analyse offers various pathways to achieving sector coupling, as we will present in the next section. After a brief presentation of these pathways, we will highlight two key findings from the analysis of recent studies: First, in general, many studies emphasize that the idea of converging infrastructures is based on more technical and social diversity, such as the parallel development and existence of different grids and infrastructure networks. Second, the assumptions made in many studies about how sector coupling and integration will come into reality show a strong reliance on politics as initiator, planner, and controller of this process. Along the lines of the questions set out in the introduction, we will discuss the fundamental socio-technical problems behind these premises of sector integration, followed by a short conclusion.

\section{The case of sector coupling}

Sector coupling as a climate protection strategy has gained considerable importance in recent years, since fossil fuels are to be gradually replaced by RES not only in the electricity sector, but 
also in the heating, cooling, and transport sectors (BMUB 2016, p. 3). Sector coupling thus embodies the structural linkage of the various industries (electricity, heating, cooling) and the mobility sector. However, as Wietschel et al. (2018, p. 3) state, there are several definitions of sector coupling, and the available studies take different disciplinary and methodological perspectives: energy system modeling (Ausfelder et al. 2017; Henning and Palzer 2015), political science and decision making (Bauknecht et al. 2018), institutional economics (Hoffrichter and Beckers 2018), social science analyses (Canzler and Knie 2013), and meta-studies (Wietschel et al. 2018; Winter 2018). A rough distinction can be made between a broad and a narrow understanding of sector coupling (Wietschel et al. 2018, p. 3).

Some authors interpret sector coupling narrowly and refer only to the conversion of RES (surplus) electricity into gases or liquids (Power-to-X) as a substitute for fossil fuels (Robinius et al. $2017 \mathrm{a}, 2017 \mathrm{~b}$ ). Others focus on all aspects associated with the coupling of energy-related sectors (e.g., also the use of waste heat) and exclude only those solutions that apply to a single sector, e. g., residential roof-mounted PV systems (Wietschel et al. 2018). Still others additionally emphasize cross-border interdependencies and the potential benefits of international cooperation as crucial aspects of sector coupling (Hoffrichter and Beckers 2018). Bauknecht et al. (2018) look beyond technical aspects and include the flexibilization also of the electricity sector and the reduction of the required expansion of the power grid, e.g., through the use of gas infrastructure.

With regard to the specific technical design of sector coupling paths, the discussed literature basically distinguishes between three options for feeding electricity from RES into the heating, cooling, and transport sectors: (1) direct electrification (e.g., electric cars or heat pumps), (2) indirect electrification divided into two sub-paths a) hydrogen (fuel cells) and b) synthetic fuels, and (3) alternative renewable energies such as biomass, solar thermal or geothermal and waste heat. Due to the limited potential of the third option in terms of energy production, the following analysis will focus on the first two. Figure 1 illustrates elements of sector coupling issues along the socio-technical problem dimensions of control, change, and action (Büscher 2018).

\section{Converging infrastructures - with or despite socio-technical diversity?}

Control problems arise from various endogenous and exogenous changes with regard to the envisioned goal of sector coupling. We need to consider technical and social operations re- sponsible for the production of goods and services as well as exogenous processes such as governance and regulation (Mayntz 2009, p. 124).

Direct electrification as a sector coupling strategy aims to replace current fossil energy use in heating and transport with renewable, low-carbon electricity. The power sector will thus become the main backbone for all energy consuming sectors (acatech et al. 2018; Ausfelder et al. 2017; Henning and Palzer 2015; Wietschel et al. 2018). From a control perspective, several challenges arise. First, end-use devices and corresponding infrastructures in the heat and transport sector need to be replaced by electrical devices. In the heat sector, oil and gas heating systems have to be replaced by electric heat pumps and/or heating networks in combination with CHP plants and increasingly with solar thermal systems, deep geothermal systems, and industrial waste heat recovery. In the transport sector, alternative drive systems such as electric and hybrid vehicles are planned to replace the internal combustion engine. In terms of infrastructure, an expansion of the capacity of vehicle and battery charging infrastructures as well as the development and expansion of the grid are necessary. Meeting the triple challenge of adjusting power supply based on wind and solar energy, expanding grid and charging infrastructure, and replacing end-use devices will be a major task (Henning and Palzer 2015).

A second challenge concerns the interplay between power production, distribution, and consumption. With the expansion of power production from renewables such as wind and solar, a paradigm shift is taking place in the energy sector. In the past, the principle "production follows consumption" meant major control efforts on the production side with control of the utilization of power plant capacity. With fluctuating renewables, the paradigm is reversed to "consumption follows production". The process of balancing electricity supply and network requirements and demand becomes more complicated (D'haese- 
leer et al. 2017). The balancing process is based on flexible load management activities focusing on all three system elements. Adjusted control activities aimed at flexibility will be more decentralized and based on highly digitalized network systems. With sector coupling, the demand side will become even more "unpredictable". While household electricity consumption is relatively easy to forecast based on the daily load profile, charging activities of electric cars, for instance, will be more randomized over day and night. Several studies discuss this challenge with regard to beneficial flexibility options for the system (Ausfelder et al. 2017; Bauknecht et al. 2018; Henning and Palzer 2015).

For indirect electrification via hydrogen and synthetic fuels, the challenge is not only to balance supply and demand, but also to establish global value and supply chains for hydrogen and e-fuel production with connected supply infrastructure for national use. There is consensus that synthetic fuels produced from RES are essential for meeting the Paris Climate Agreement and should be used in transport where no low-carbon alternatives are available (e.g., aviation and shipping) and in energy-intensive industry sectors. Due to structural cost disadvantages for domestic production, supply chains abroad are favored (acatech et al. 2018). Most advocates favor a strategy with technology innovation and development in Germany, followed by an upscaling of Power-to-X technology abroad (e. g., Norway, Morocco, Dubai, or Australia). However, from a control perspective, it is unclear how to steer and manage the establishment of production and supply chains for hydrogen and e-fuels (Hoffrichter and Beckers 2018; Winter 2018).

When combining several sector coupling pathways, an additional control challenge becomes apparent. Different networks and infrastructures are required to implement the different paths (direct and/or indirect electrification). Depending on political and societal priorities the system requires different networks. tablished (see Dekker and van Est in this volume). This raises the question of how operators and supervisors can control parallel grids and networks in terms of service security (vulnerability and resilience), safety (data integrity and privacy), and cost efficiency.

\section{Change strategies for converging infrastructures}

The energy transition, and thus increased sector coupling, is a huge technical and social experiment which has must find a balance between sufficient redundancy and appropriate variance in infrastructure operations (Büscher 2018, p. 23 f.). Given a steadily increasing share of RES, the challenge is no longer the supply of energy, but rather to manage supply and demand accordingly, especially in times of low RES-based energy supply (Bauknecht et al. 2018, p. 40 f.). In this situation, planned (policy) instruments and evolutionary events factor into the process of change. According to current logic, many interventions are conceptualized as a linear cause-effect relationship in which incentives should lead to market and behavioral changes (acatech et al. 2018, p. 4; Wietschel et al. 2018, p.6f.; Winter 2018, p. 16f.). In energy system modeling, this is usually implemented by assuming specific RES shares in energy production, energy efficiency progress, and/or price elasticities of the actors or policy instruments such as regulation or funding programs. However, barriers, e. g., regarding the adoption of climate-friendly technologies, or bounded rationalities, such as a lack of information, are often disregarded.

With converging infrastructures, we must also assume that new actor structures and market opportunities will emerge. The transformation process from today's centralized to decentralized

\section{An expansion of the capacity of vehicle and battery charging infrastructures as well as the development and expansion of the grid are necessary.}

These are electricity networks (both transmission and distribution networks), gas, hydrogen, and heating networks, electricity grids for overhead line trucks as well as rail and road networks and intelligently communicating supply networks (smart grids). Besides these network expansion activities, various types of storage (battery, heat, gas, and hydrogen storage) may be needed (acatech et al. 2018; Schwan et al. 2016). Furthermore, in line with the increasing flexibility of the system, local demand side management (smart meters), consumption and storage partnerships through links to other consumption areas such as mobility, battery electric vehicles as storage (vehicle to grid), and electricity self-consumption will have to be es- supply structures is influenced by many actors and is associated with uncertainties (Bauknecht et al. 2018, p. 36 f.). The likelihood of (sustainable) innovations increases in less regulated, but protected niches (Geels and Schot 2007). The engagement of private individuals (e.g., system-oriented "prosuming" through energy self-consumption by household PV systems), new cooperatives, and new business perspectives (i. e., new business models) even for already established companies fundamentally change the constellation of actors within the system.

In addition, for an (internationally) consistent sector coupling strategy, cross-border interdependencies and international cooperation must be considered (D'haeseleer et al. 2017, p. 67). The 
coordination of national measures to transform European energy systems can be seen as a prerequisite for the development of efficient sector coupling solutions (Hoffrichter and Beckers 2018, p. 48). Political interventions such as, e.g., the internalization of external costs through a $\mathrm{CO}_{2}$ price, an expanded emissions trading system (ETS) or through a $\mathrm{CO}_{2}$-oriented reform of electricity and energy taxes, are crucial for the success of the sector coupling process (acatech et al. 2018, p. 4; Wietschel et al. 2018, p. 6 f.; Winter 2018, p. 16 f.). Several approaches are available, ranging from a centralized governance model (e. g., transnational energy-only market) to a decentralized governance model (Hoffrichter and Beckers 2018, p. 22 f.). In this context, many is-

\section{The energy transition, and thus} increased sector coupling, is a huge technical and social experiment.

sues remain unresolved, such as the structure of adequate longterm governance and the coordination of decision-making processes involving the EU, national, and local levels in the context of sector coupling.

Most studies of sector coupling assume that politics is the main driver for a far-reaching convergence of energy/electricity, transport, heating and cooling. Therefore, action is supposed to be based on political programs that provide incentives for desired transactions (for example via price signals) leading to research and development of technologies and investment in new technologies that promote sector coupling. Uncertainty, then, is a stimulus for innovation, but only if politics is committed to the overall goal of the energy transition in the long term (Canzler and Knie 2013, p. 15). All studies emphasize that trust in long-term, reliable, and transparent political programs is the fundamental mechanism of uncertainty absorption and thus stimulus for risk taking and action by the industry (acatech et al. 2018, p. 53).

On the other hand, the reviewed studies analyze political risks without giving any indication how political decision-makers might cope with uncertainty. A general problem is the lack of acceptance of large scale infrastructure projects such as transmission lines, which particularly hinders the development path of direct or high degree of electrification (Ausfelder et al. 2017, p.59). Specific problems that may arise are:

- failing subsidy allocation and free-rider effects resulting in undesired exploitation (deadweight effects) where companies receive financial resources they would have invested anyway (Ausfelder et al. 2017, p. 141);

- failing incentives where too low a price (a tax or a certificate) might not motivate people to invest in energy efficiency, renewable energies, and technologies for coupling the energy sectors (acatech et al. 2018, p. 59);
- economic inefficiency of technology-specific regulations, which might hinder transparent competition between different technologies in achieving political goals such as reducing $\mathrm{CO}_{2}$ emissions (acatech et al. 2018, p. $55 \mathrm{f}$.);

- migration of businesses due to resistance from energy-intensive industries to higher prices (via taxes or certificates) and possible relocation of production sites if these prices remain a purely national policy and are not applied in the EU and elsewhere (acatech et al. 2018, p. 58; Ausfelder et al. 2017, p. 131).

As for the role of the "prosumer", non-professional users have to take risks in future integrated and smart infrastructures. One aspect is the complexity of smart grids, in which RES technologies and information technologies represent novel possibilities for electricity supply, transport, and heating. Novel control technologies might burden users who normally rely on simplification and routine behavior (Canzler and Knie 2013, p. 95). The other aspect is that the costs of shared infrastructure in communal projects increases the risk for participants and their financial commitments (Canzler and Knie 2013, p. 94).

All in all, we find no evidence that the studies consider uncertainty and risk in the operation of converging infrastructures. After all, the developments in question touch on issues such as centralization vs. decentralization: If more complicated tight couplings are introduced in future infrastructures, the danger of systemic risk might increase (Hellström 2009, p. 327). Failures in one part of the overall complex can lead to a cascade of failures in other parts if sectors (systems) become increasingly coupled. On the other hand, with the emergence of a more decentralized energy system, more redundancies come into effect, which might increase the resilience of the overall complex (Kröger and Nan 2018). The issue of integration vs. disintegration also moves into the focus. US and European policy has for decades supported vertical disintegration along the value chain of energy supply, transmission, and distribution (unbundling) to promote more market-oriented coordination (Coutard 1994). In sector coupling, on the other hand, system planners and supervisors focus on horizontal integration - via the coupling of different infrastructures. This means, for example, that any regulatory attempt must account for the consequences of decision making in a much larger and more complex entity. Planning and risk assessment are thus faced with new problems of responsibility and liability.

\section{Conclusion}

The future of converging infrastructures through sector coupling is a visionary and ambitious project, which may entail a heavy burden of increased complexity and contingency as well as increased uncertainty and the need for risk-taking. In addition, the energy transition is subject to constant technological change and occasional disruptive events, such as accidents (Fukushima) or 
crisis situations (coronavirus pandemic), which may fundamentally change the conditions of planned action programs.

The studies we analyzed describe a coherent set of commonly shared goals, seeing sector coupling as a promising strategy to increase resource and energy efficiency and reduce greenhouse gas emissions. Against this background, the studies focus on laying out a variety of optional sector coupling pathways that are generally considered feasible, efficient, and effective. The main pathways refer to direct or indirect electrification (sometimes a third pathway is added, namely alternative renewable energy
Finally, it remains largely unclear how the overall change process toward sector coupling is initiated and triggered. We have noted an almost complete reliance on politics, which is expected to implement financial incentives or subsidies. Although politics is seen as the central actor in steering the sector coupling process, the interaction between different actors (e. g., business, municipal actors, or civil society, etc.) is not discussed. Very few studies elaborate on bottom-up activities to stimulate sustainable innovations (see Ornetzeder and Sinozic in this volume). Finally, the decision-making process for sector coupling in a multi-level

\title{
Although politics is seen as the central actor
}

\author{
to steering the sector coupling process, interaction between \\ different actors needs to be analyzed more closely.
}

sources). The set of optional pathways includes volumes (of energy sources) and capacities (of transport, distribution, and consumption, respectively), technical needs and future options, feasibility and compatibility, as well as market requirements and macroeconomic efficiency. However, several issues remain open as to how to make this vision a reality.

The conceptualized pathways assume a degree of social behavioral adaptation, with investment and routine braking consumption decisions that are hard to realize. There are lock-in effects (e. g., long investment cycles for certain technologies), trade-offs, and inefficiencies due to structural and individual behavioral decision-making traditions that hinder action and change in sector coupling. The elaborated sector coupling pathways highlight the paradigms of technical feasibility and economic efficiency, underestimating the (assumed) requirements and consequences for consumer action and institutional decision making alike. The techno-economic optimization approach must be complemented by implementation research considering power structures and individual decision making.

Also, innovation and exnovation management and regulation strategies will play a central role in successful sector coupling strategies (David and Gross 2019). There is some discussion about the transition process with a parallelism between the shutdown of old and the opening of new technology pathways (such as the fossil fuel phase-out). However, in particular with regard to the transport sector, efforts to proactively manage defossilization and thereby the "exnovation" of fossil-fuel-based technologies are currently less apparent. With regard to behavioral changes and the diffusion of technologies, the studies mostly assume linear cause-effect relationships (with a focus on $\mathrm{CO}_{2}$ prices through taxation, subsidies, or ETS) - in the hope of achieving desired effects. Socio-technical dynamics in the change process - such as varying acceptance depending on the technological solution or varying degrees of willingness to change behavior in society - are ignored. governance system (interplay of local, federal, national, or even European and global levels) needs to be specified. Among the optional sector coupling pathways, policy makers need to prioritize and decide on the pathways to follow.

\section{Acknowledgement}

We would like to thank our former colleague Chiara lurato who gave us valuable and creative input for the conceptual idea of this paper.

\section{References}

acatech - National Academy of Science and Engineering; Leopoldina - German National Academy of Sciences; Akademieunion - Union of the German Academies of Sciences and Humanities (2018): Coupling the different energy sectors. Options for the next phase of the energy transition. Munich: acatech - National Academy of Science and Engineering; Leopoldina German National Academy of Sciences; Akademieunion - Union of the German Academies of Sciences and Humanities.

Ausfelder, Florian et al. (2017): Sektorkopplung. Untersuchungen und Überlegungen zur Entwicklung eines integrierten Energiesystems. Munich: acatech National Academy of Science and Engineering; Leopoldina - German National Academy of Sciences; Akademieunion - Union of the German Academies of Sciences and Humanities.

Bauknecht, Dierk et al. (2018): Visionen und Pfadentscheidungen der Energiewende. Ein Bericht im Rahmen des Kopernikus-Projekts ENavi. Potsdam: Geschäftsstelle des Kopernikus-Projekts Energiewende-Navigationssystem I ENavi.

Beckman, Svante (1994): On systemic technology. In: Jane Summerton (ed.): Changing large technical systems. Boulder: Westview Press, pp. 311-331. BMUB - Bundesministerium für Umwelt, Naturschutz, Bau und Reaktorsicherheit (2016): Klimaschutzplan 2050. Klimaschutzpolitische Grundsätze und Ziele der Bundesregierung. Berlin: Bundesministerium für Umwelt, Naturschutz, Bau und Reaktorsicherheit.

Büscher, Christian (2018): Framing energy as a sociotechnical problem of control, change, and action. In: Christian Büscher, Jens Schippl and Patrick Sumpf (eds.): Energy as a sociotechnical problem. An interdisciplinary 
perspective on control, change, and action in energy transitions. London: Routledge, pp. 14-38.

Canzler, Weert; Knie, Andreas (2013): Schlaue Netze. Wie die Energie- und Verkehrswende gelingt. Munich: Oekom.

Coutard, Olivier (1994): Economics of grid systems in reconfiguration. Competition in the electricity supply industry. In: Jane Summerton (ed.): Changing large technical systems. Boulder: Westview Press, pp. 163-189.

David, Martin; Gross, Matthias (2019): Futurizing politics and the sustainability of real-world experiments. What role for innovation and exnovation in the German energy transition? In: Sustainability Science 14 (4), pp. 991-1000.

D'haeseleer, William; de Vries, Laurens; Kang, Chongqing; Delarue, Erik (2017): Flexibility challenges for energy markets. Fragmented policies and regulations lead to significant concerns. In: IEEE Power and Energy Magazine 15 (1), pp. 61-71.

Edwards, Paul (2004): Infrastructure and modernity: Force, time, and social organization in the history of socio-technical systems. In: Thomas Misa, Philip Brey and Andrew Feenberg (eds.): Modernity and technology. Cambridge: MIT Press, pp. 185-225.

Franssen, Maarten; Kroes, Peter (2009): Sociotechnical systems. In: Jan Olsen, Stig Pedersen and Vincent Hendricks (eds.): A companion to the philosophy of technology. Chichester: Wiley-Blackwell, pp. 223-226.

Geels, Frank; Schot, Johan (2007): Typology of sociotechnical transition pathways. In: Research Policy 36 (3), pp. 399-417.

Hellström, Tomas (2009): New vistas for technology and risk assessment? The OECD programme on emerging systemic risks and beyond. In: Technology in Society 31, pp. 325-331.

Henning, Hans-Martin; Palzer, Andreas (2015): Was kostet die Energiewende? Wege zur Transformation des deutschen Energiesystems bis 2050. Freiburg: Fraunhofer ISE.

Hoffrichter, Albert; Beckers, Thorsten (2018): Cross-border coordination as a prerequisite for efficient sector coupling in interconnected power systems. Institutional economic considerations on allocating decisionmaking competencies in the European Union. Berlin: Technische Universität Berlin.

Kröger, Wolfgang; Nan, Cen (2018): Power systems in transition. Dealing with complexity. In: Christian Büscher, Jens Schippl and Patrick Sumpf (eds.): Energy as a sociotechnical problem. An interdisciplinary perspective on control, change, and action in energy transitions. London: Routledge, pp. 41-78.

Mayntz, Renate (2009): The changing governance of large technical infrastructure systems. In: Renate Mayntz (ed.): Über Governance. Institutionen und Prozesse politischer Regelung. Frankfurt am Main: Campus Verlag, pp. 121-150.

Nightingale, Paul; Brady, Tim; Davies, Andrew; Hall, Jeremy (2003): Capacity utilization revisited. Software, control and the growth of large technical systems. In: Industrial and Corporate Change 12 (3), pp. 477-517.

O'Malley, Mark; Kroposki, Benjamin (2017): Unlocking flexibility. Energy systems integration. In: IEEE Power and Energy Magazine 15 (1), pp. 10-14

Robinius, Martin et al. (2017 a): Linking the power and transport sectors. Part 1: Modelling a sector coupling scenario for Germany. In: Energies 10 (7), p. 22. DOI: $10.3390 / e n 10070956$.

Robinius, Martin et al. (2017 b): Linking the power and transport sectors. Part 2: Modelling a sector coupling scenario for Germany. In: Energies 10 (7), p. 23. DOI: $10.3390 /$ en10070957.

Schwan, Gesine; Treichel, Katja; Höh, Anne (2016): Sektorkopplung. Von der Stromwende zur Energiewende. Berlin: HUMBOLDT-VIADRINA Governance Platform.

Wietschel, Martin et al. (2018): Sektorkopplung. Definition, Chancen und Herausforderungen. Karlsruhe: Fraunhofer ISI.

Winter, Martin (2018): Effiziente Kopplung der Sektoren Energie und Verkehr. Berlin: Technische Universität Berlin.

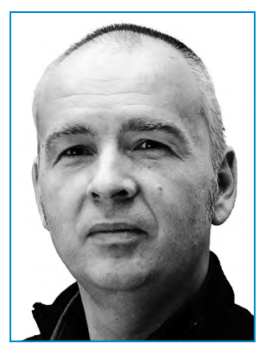

DR. CHRISTIAN BÜSCHER

is since 2006 member of scientific staff at the Institute for Technology Assessment and Systems Analysis (ITAS). His research topics cover the theoretical embedment of technology assessment, social science-based energy research and risk and ecological sociology.
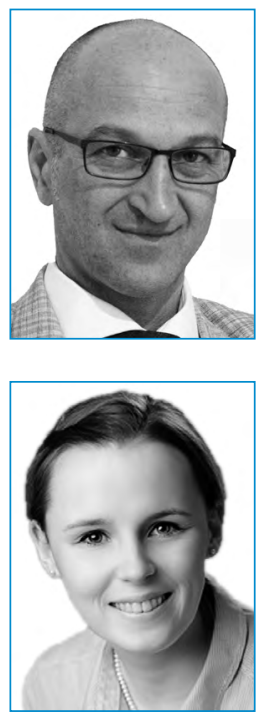

\section{DR. DIRK SCHEER}

works since 2017 as senior researcher at the Institute for Technology Assessment and Systems Analysis (ITAS). His research interests are on socialscience based energy research, technology acceptance research, knowledge transfer and management at the science-policy interface, participation and risk research, and future knowledge.

\section{LISA NABITZ}

joined ITAS in 2017 as member of the scientific staff. Her focus is on social science analyses on the German energy transition (Energiewende), design and evaluation of energy policy instruments, energy efficiency in industry, transitions research, MultiLevel Perspective (MLP), and Technological Innovation System (TIS) research. 


\title{
Sector coupling technologies in gas, electricity, and heat networks
}

\author{
Competition or synergy?
}

Stella Oberle, Fraunhofer Institute for Systems and Innovation Research ISI, Breslauer Str.48, 76139 Karlsruhe (stella.oberle@isi.fraunhofer.de) (1) https://orcid.org/0000-0003-0780-7133

Judith Stute, Fraunhofer Institute for Systems and Innovation Research ISI (judith.stute@isi.fraunhofer.de) (1) https://orcid.org/0000-0003-3853-5281

Markus Fritz, Fraunhofer Institute for Systems and Innovation Research ISI (markus.fritz@isi.fraunhofer.de)

Marian Klobasa, Fraunhofer Institute for Systems and Innovation Research ISI (marian.klobasa@isi.fraunhofer.de)

Martin Wietschel, Fraunhofer Institute for Systems and Innovation Research ISI (martin.wietschel@isi.fraunhofer.de)

Current investment in distribution networks for electricity, gas, and heat is high, and the distribution networks play a prominent role in the necessary transformation of the energy system. This paper provides insights into the relationship between residential end-user decisions on heat supply and their effect on infrastructure planning. Therefore, the gas, electricity, and heat networks are analyzed together. After a review of the characteristics of the networks, the most common sector coupling technologies are compared economically and environmentally. The results show that, under the assumptions made, heat pumps are the cheapest option for residential end-users in the long run. This raises the question of whether a parallel development of three different infrastructures for the heat supply of buildings is the best path to a successful energy transition.

\section{Sektorkopplungstechnologien in Gas-, Strom- und Wärmenetzen Konkurrenz oder Synergie?}

Die derzeitigen Investitionen in die Verteilnetze für Strom, Gas und Wärme sind hoch und die Verteilnetze spielen eine bedeutende Rolle bei der notwendigen Transformation des Energiesystems. Diese Arbeit gibt Einblicke in den Zusammenhang zwischen Entscheidungen privater Endnutzer zur Wärmeversorgung und deren Auswirkungen auf die Infrastrukturplanung. Dafür werden die Gas-, Strom- und Wärmenetze gemeinsam analysiert. Nach einem Überblick über die Charakteristika der Netze werden die gängigsten Sektorkopplungstechnologien ökonomisch und ökologisch verglichen. Die Ergebnisse zeigen, dass unter den getroffenen Annahmen Wärmepumpen langfristig die kosten-

This is an article distributed under the terms of the Creative Commons Attribution License CCBY 4.0 (https://creativecommons.org/licenses/by/4.0/)

https://doi.org/10.14512/tatup.29.2.24

Submitted: 17. 02.2020. Peer reviewed. Accepted: 15.05.2020 günstigste Option für private Endnutzer sind. Dies wirft die Frage auf, ob eine parallele Entwicklung von drei verschiedenen Infrastrukturen zur Wärmeversorgung von Gebäuden der beste Weg hin zu einer erfolgreichen Energiewende ist.

Keywords: gas network, electricity network, heat network, end-user perspective, infrastructure planning

\section{Introduction}

The national and international commitments to curb greenhouse gas (GHG) emissions (UNFCCC 2015; BMU 2016) make the reduction of fossil energy sources to a minimum by 2050 a necessity. Achieving this requires a fundamental transformation of not only the energy sector, but also changes in the demand sectors of households, transport, trade, commerce, and services (TCS), and industry.

With a share of $23.8 \%$ in Germany in 2017 (AGEB 2018), natural gas is the second most important primary energy source after mineral oils. Natural gas is also used as a final energy source in almost every sector. Only in the transport sector is it less relevant with minor market shares of natural gas-powered passenger cars. However, there is a growing focus on alternatives, especially regarding buildings (households and TCS). For example, heat pumps are increasingly used to supply heat to highly insulated buildings and are being installed in heat networks (district heating).

Various studies, investigating a significant GHG reduction of $95 \%$ until 2050 compared to 1990 , indicate a clear decline in the demand for natural gas by 2050 (dena 2018; BCG and prog- 
nos 2018; Öko-Institut and Fraunhofer ISI 2015). These studies point to a move from heat generation based predominantly on natural gas to electricity-based heat by 2050 , especially concerning buildings. Such a strong drop in the demand for natural gas in a gas distribution network, assuming its size remains unchanged, results in a sharp rise in the specific operating costs (Wachsmuth et al. 2019) and casts doubt on the economic efficiency of a natural gas distribution network for supplying heat to buildings.

To analyze the competitive situation of the natural gas distribution network, the gas, electricity, and heat distribution infrastructures are analyzed together. The definition of sector coupling is broadly discussed in the literature (Wietschel et al. 2018 b; Scorza et al. 2018; bdew 2017). We understand sector coupling as the linking of the sectors electricity and heat with their infrastructure, i. e. a stronger coupling of the grid-bound energy sources electricity, heat and gas. The technologies, that couple the networks with each other, differ depending on the demand sector. We will focus on the building sector. In this sector, gas boilers and to a limited extent combined heat and power plants (CHP) are connected to the natural gas distribution network. The electricity distribution network supplies heat pumps and electric heating appliances as well as night storage heaters, the latter to a limited and declining extent. Alongside oil-based options, these compete with gas boilers and heat networks to supply buildings with heat. A strong synergy emerges between the electricity distribution network and heat networks if the latter are supplied with heat from large heat pumps or electric heating rods. Otherwise, when using geothermal or solar thermal technologies as a heat source, the heat networks compete with natural gas and electricity distribution networks to supply heat to buildings.

The objective of the paper is to provide insights into the connection between residential end-user decisions and their potential effect on infrastructure planning. These insights then contribute to the question of the role to be played by the gas distribution network in the energy system of the future. As a first step, the characteristics of the three infrastructures and the current regulatory framework are described and the most relevant sector coupling and competing options are pointed out. Subsequently, an economic comparison and a comparison based on $\mathrm{CO}_{2}$ emission of those technologies in Germany is made, to provide insights into the basis of decision-making for residential end-users, and the results are explained.

\section{Perspective of network operators: characteristics of the infrastructures}

The annual investment and service and maintenance expenses of gas and electricity distribution networks are nearly double the expenses of their transport networks, so that infrastructure changes will lead to higher expenses on the distribution network level than on the transport network level. Comparing the investments per kilometer expanded in electricity and gas distribution networks reveals that specific investments in electricity $(624,584 € / \mathrm{km})$ are much higher than in gas $(90,162 € / \mathrm{km})$ (BNetzA and Bundeskartellamt 2019). The cost of building heating networks is $50,000 € / \mathrm{km}$ under very favorable conditions and can be up to $800,000 € / \mathrm{km}$ under unfavorable conditions (for example in dense urban areas) (Clausen 2012). On the other hand, the service and maintenance expenses for the total length of the distribution networks are significantly higher for the gas distribution network, with $2,105 € / \mathrm{km}$, than for the electricity grid, with $1,734 € / \mathrm{km}$. Furthermore, the energy transported via the gas distribution network was 754 TWh in 2018. This is considerably more than via the electricity distribution grid, which was only 443 TWh (BNetzA and Bundeskartellamt 2019).

The expansion and maintenance of the gas and electricity distribution networks is planned and implemented by the respective distribution network operator (DSO) separately, according to the amount of energy purchased in a network area. This is done due to the link between rising costs and decreasing demand. For example considering the situation for gas distribution networks, there is a clear increase in the specific operating costs if the length of the gas network remains the same but there is a drop in the demand for gas.

So-called network charges distribute the costs for building, operating, maintaining and expanding the gas and electricity networks across all network users (BNetzA and Bundeskartellamt 2019). Broadly speaking the higher the utilization of electricity or gas networks is, the wider the cost can be spread among network users; a lower rate of utilization of the infrastructure leads to higher individual costs for the remaining network users. With a $22.3 \%$ share of the German average electricity price of $30.85 € \mathrm{ct} / \mathrm{kWh}$, the electricity network charges for transportation and distribution networks have a similar share of prices to those of the gas network charges, which account for $23.3 \%$ of the average German gas price of $6.34 € \mathrm{ct} / \mathrm{kWh}$ for household customers (BNetzA and Bundeskartellamt 2019). However, at nearly a quarter of the price, the network charges, and consequently the infrastructure cost, have a strong influence on the end-user price.

\section{Perspective of residential end-users: sector coupling and competing technologies}

Since the distribution network level is of particular importance, we focus on heat supply in the residential building sector. In particular, the technologies with the highest relevance - gas boilers, heat pumps and a connection to a heat network supplied by a large heat pump - are considered in more detail. BDEW (2019) shows that user satisfaction is highest with these selected technologies.

Efficient gas condensing boilers are the current state-of-theart technology capable of achieving an efficiency of more than $90 \%$ (Hirzel 2017). With a view to decarbonization, a move 
from natural gas to synthetic methane, produced using electricity, by 2050 is being discussed. Synthetic methane can be fed into the gas distribution network without any additional modifications and can be used to fuel condensing boilers (Viebahn et al. 2018). Condensing boilers are promoted in Germany by the nationwide funding offered by the Kreditanstalt für Wiederaufbau (KfW) and the Federal Office for Economic Affairs and Export Control (BAFA). The KfW funds the conversion of gas heating systems to condensing boiler technologies with low-interest loans of up to $€ 50,000$ or with subsidies of $20 \%$, which can range between $€ 300$ and $€ 10,000$ (KfW 2020). BAFA funds up to $20 \%$ of the eligible costs of converting an existing boiler to a condensing one if solar thermal is installed as well (BAFA 2019).

The sales figures for heat pumps in Germany show that electricity-based air heat pumps are currently preferred (BWP 2019). The efficiency of such a system is measured using the so-called annual coefficient of performance (COP), which represents the ratio between the amount of heat supplied and the amount of power used (Wietschel et al. 2018a). The COP of such devices depends heavily on the heat source used and is on average around 3.0 for air heat pumps (Miara et al. 2011). To ensure their efficient operation, the temperature difference between the heat source and the heating system should be as low as possible, which is why its performance is best in well-insulated buildings (Wietschel et al. 2018 a). BAFA funds heat pumps through the KfW mainly via loans with a repayment bonus or investment subsidies for energy-related (complete) renovations (BWP 2020). For air heat pumps this funding is $45 \%$ of the eligible costs when substituting oil-based heating in existing buildings and $35 \%$ when replacing a different kind of heating system. The required COP of the heat pumps is $\geq 3.8$ (BWP 2020). For new buildings, the funding is also $35 \%$ of the eligible costs, but the required COP is $\geq 4.5$ (BWP 2020).

Large heat pumps installed in heat networks function in a similar way to other heat pumps. As a private person, a subsidy for establishing a connection to a district heating network can be granted in Germany under the KfW subsidy program No.430. A subsidy of $10 \%$ is granted up to a maximum amount of $€ 5,000$ per housing unit (KfW 2019).

\section{Comparison of sector coupling and competing technologies}

To provide a clearer picture of the possible heat production options for residential end-users this section compares the sector coupling technologies described above using a defined case study regarding environmental and economic aspects. The analysis includes the different framework conditions of single-family houses (SFH) and multi-family houses (MFH) in existing buildings and new buildings for 2015 and 2050. The economic analysis also considers the current funding possibilities. It is assumed that these subsidies will no longer apply in 2050. Further the comparison is based on useful energy. This is the part of energy that is left after converting the final energy, such as electricity or natural gas, into - for example - light or heat.

The existing SFH considered has a floor area of $140 \mathrm{~m}^{2}$ and currently a heating demand of $236 \mathrm{kWh} / \mathrm{m}^{2}$ and therefore an annual heating demand of $33,040 \mathrm{kWh}_{\text {useful energy }}$ (dena 2016). In 2050 the existing SFH assumed has a heating demand of $40 \mathrm{kWh} / \mathrm{m}^{2}$, because the buildings newly constructed in 2015 will be the existing buildings in 2050. A newly built SFH has an annual heating demand of $5,600 \mathrm{kWh}_{\text {useful energy }}$ for the same floor area in 2015 and 2050 (dena 2016). The MFH is assumed to be a five-story building with two apartments per story, each with a floor area of $80 \mathrm{~m}^{2}$. This results in a heating energy demand of $132,800 \mathrm{kWh}_{\text {useful energy }}$ per year for existing buildings in 2015 and 32,000 $\mathrm{kWh}_{\text {useful energy }}$ per year in new buildings in 2015 and 2050 as well as in existing buildings in 2050. These cases are only examples of current buildings. The structure of buildings and therefore their heating demand varies very widely. This is the case in both new buildings and existing buildings. Heating demand can range from below $100 \mathrm{kWh} / \mathrm{m}^{2}$ to more than $500 \mathrm{kWh} / \mathrm{m}^{2}$ (Häupl et al. 2017). These examples only represent conditions in a "typical" building and are taken from the dena report on buildings in Germany (dena 2016).

\section{Economic perspective: costs, prices, and taxes/duties}

The economic comparison is conducted from the point of view of the residential end-user and therefore shows which technologies are the cheapest solution for him/her. Tab. 1 provides an overview of the assumed investments and costs that are used to determine capital costs. With regard to funding, subsidies of $20 \%$ are assumed for gas condensing boilers, 35\% for heat pumps, and $10 \%$ for heat networks (see the section "Perspective of residential end-users: sector coupling and competing technologies"). For the existing buildings, it is assumed that the required heat pump COP of 3.8 cannot be achieved without an expensive (partial) refurbishment. Therefore, no subsidy is assumed for existing buildings and we consider a COP of 2.8.

For the operating costs of the different technologies, today's energy prices and the price development until 2050 are estimated based on various studies. The same studies show that for achieving a $95 \%$ GHG reduction in 2050 compared to 1990 , natural gas needs to be replaced by carbon-neutral synthetic methane (BCG and prognos 2018; dena 2018; Öko-Institut and Fraunhofer ISI 2015). The comparison for 2050 contains synthetic methane imported from North Africa. The Power-to-Gas and Power-to-Liquid (PtG/PtL) calculator of Frontier Economics (2017) was used to determine the costs for synthetic methane and $0.43 € \mathrm{ct} / \mathrm{kWh}$ was added for sales (Agora Energiewende and Frontier Economics 2017) plus another $10 \%$ margin to obtain the price without taxes and levies. The assumed maintenance costs, as well as the efficiency developments of the technologies are based on Hirzel (2017), Viebahn et al. (2018) and Wietschel et al. (2018a). 


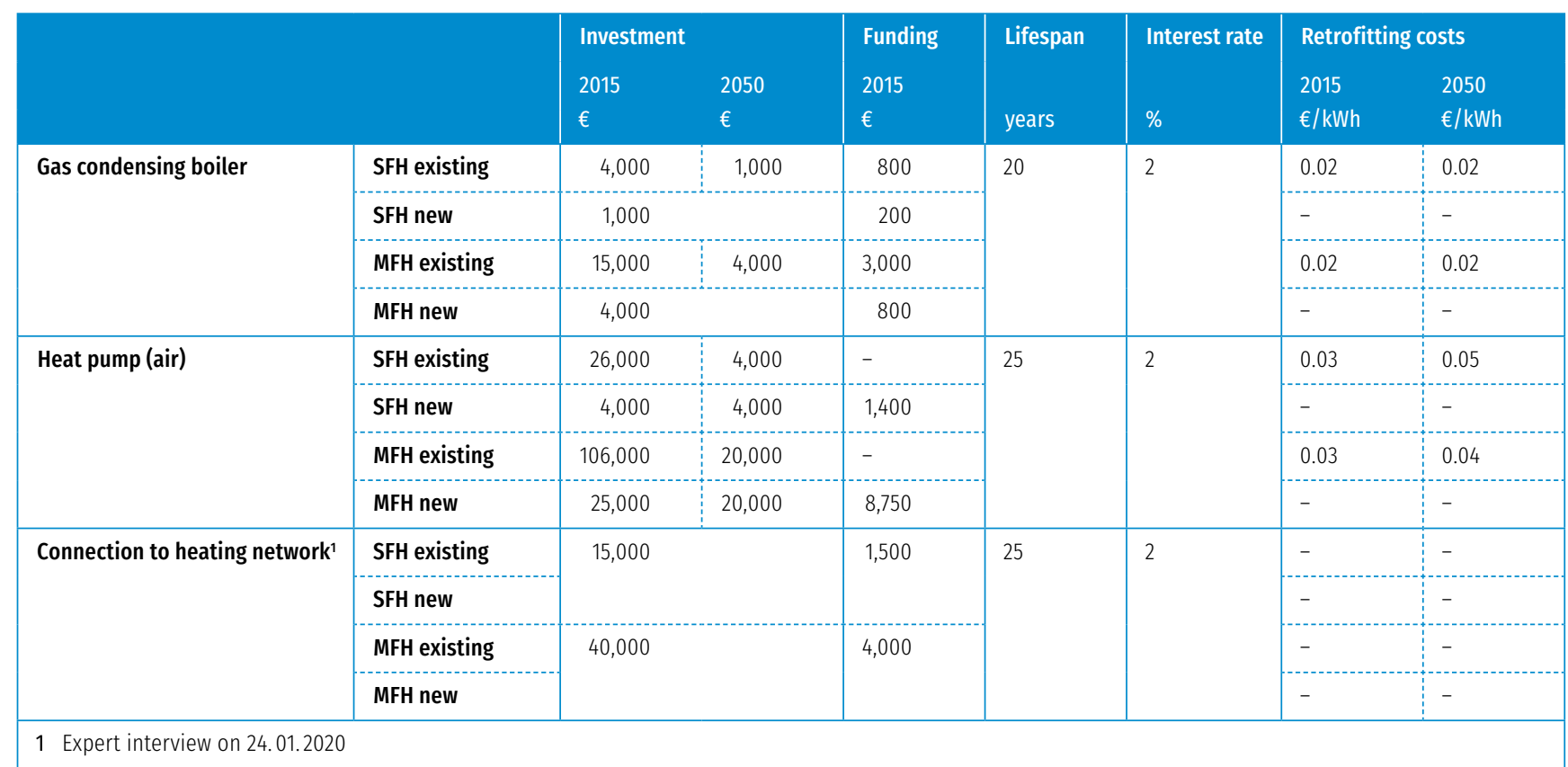

Tab.1: Assumptions for the derivation of capital expenditures for the coupling technologies. Source: Wietschel et al. (2018 a), Clausen (2012), Henning and Palzer (2015)

\begin{tabular}{|c|c|c|c|c|c|}
\hline & & $\begin{array}{l}\text { Gas condensing boiler/gas } \\
\text { existing buildings new buildings }\end{array}$ & $\begin{array}{l}\text { Heat pump/electr } \\
\text { existing buildings }\end{array}$ & new buildings & $\begin{array}{l}\text { Connection to heating network/heat } \\
\text { existing buildings new buildings }\end{array}$ \\
\hline \multirow[t]{2}{*}{ Efficiency in \% } & 2015 & 90 & $280^{1}$ & $450^{1}$ & 100 \\
\hline & 2050 & & $450^{1}$ & $450^{1}$ & \\
\hline \multirow{2}{*}{$\begin{array}{l}\text { Average energy carrier price } \\
\text { for households (after-tax) } \\
\text { in €ct/kWh }\end{array}$} & 2015 & 6.3 & \multicolumn{2}{|l|}{21.7} & 8.9 \\
\hline & 2050 & 15.4 & \multicolumn{2}{|l|}{27.0} & 12.0 \\
\hline \multirow{2}{*}{$\begin{array}{l}\text { Average energy carrier price } \\
\text { for households (pre-tax) } \\
\text { in €ct/kWh }\end{array}$} & 2015 & 4.8 & \multicolumn{2}{|l|}{10.6} & 7.5 \\
\hline & 2050 & 5.3 & \multicolumn{2}{|l|}{13.1} & 10.1 \\
\hline $\begin{array}{l}\text { Price for synthetic methane } \\
\text { (pre-tax) in €ct/kWh }\end{array}$ & 2050 & 20.9 & \multicolumn{2}{|l|}{-} & - \\
\hline \multirow[t]{2}{*}{ Maintenance costs in $€ c t / k W h$} & 2015 & \multirow[t]{2}{*}{1.3} & \multirow[t]{2}{*}{1.4} & \multirow[t]{2}{*}{2.3} & \multirow[t]{2}{*}{-} \\
\hline & 2050 & & & & \\
\hline \multicolumn{6}{|c|}{$\begin{array}{l}1 \text { As explained in the section "Perspective of residential end-users: sector coupling and competing technologies", the COP can be approximately defined as the } \\
\text { efficiency. The COP represents the ratio between the amount of heat supplied to the amount of power used, which in turn means that it can be higher than } 100 \% \text {. }\end{array}$} \\
\hline
\end{tabular}

Tab.2: Development of the efficiency of three sector coupling technologies and assumed price development of the four network-based energy carriers.

Source: Hirzel (2017), Viebahn et al. (2018), Wietschel et al. (2018a), dena (2018), BCG and prognos (2018), Öko-Institut and Fraunhofer ISI (2015), Agora Energiewende and Frontier Economics (2017), WIBERA (2017), BNetzA and Bundeskartellamt (2019)

Tab. 2 provides an overview of the assumptions used to calculate the operating costs. The price of district heating up to 2050 was based on a linear extrapolation of prices according to WIBERA (2017). Comparing the difference of the average energy carrier price after taxes and pre-taxes shows the high tax burden on electricity compared to gas and heat.
Based on the assumptions described above, the capital and operating costs are calculated per kWh of useful energy (heat). Fig. 1 shows the results for investments and operating costs broken down by building category and technology. Operating costs are further split into on the one hand network charges and on the other hand other taxes, levies and charges. For SFH and MFH 
in new buildings the heat pump is already the most favorable solution today and continues to be so in 2050, with the expenditures in SFH being $18.4 € \mathrm{ct} / \mathrm{kWh}_{\text {useful en- }}$ ergy less than a connection to the heating network in 2050 and potential savings of $11.2 € \mathrm{ct} / \mathrm{kWh}_{\text {useful energy }}$ for MFH. The specific costs of heat pump use in new buildings are lower than in existing buildings, as a higher COP can be achieved. For existing buildings, a gas condensing boiler running on natural gas is the cheapest technology option today, with only a difference of approximately $0.6 € \mathrm{ct} / \mathrm{kWh}_{\text {useful }}$ energy compared to heat pumps. Connecting to the heating network is the most expensive solution for all building categories in 2015. In new buildings especially, the specific costs are significantly higher than for the other technologies, because the connection to the heating network leads to fixed costs and is not measured according to heating capacity.

Overall, the costs (excluding inflation) will increase in 2050 for all technology options. This is partly due to the rising energy carrier costs and partly due to subsidies no longer being available. Due to the high fuel costs the use of synthetic methane will not be competitive compared to the other heating technologies in 2050. For the network charges which include the infrastructure costs spread across the network users, the assumption is made that the share of network charges of the energy carrier price will stay constant until 2050 , due to high uncertainties in their future development, leading to a slight increase in absolute network charges.

\section{Environmental perspective: $\mathrm{CO}_{2}$ emissions}

To compare the environmental impact of the different technologies, an emission factor of $62.33 \mathrm{t}_{\mathrm{CO} 2} / \mathrm{TJ}_{\text {useful energy }}$ is assumed for natural gas today and in 2050 (European Commission 2007). The current power mix is applied to heat pumps today (UBA 2019), and carbon-neutral electricity generation is assumed for 2050, without biomass and fossil fuels. GHG emissions caused indirectly or along the upstream, such as during the production of PV and wind power installations, are not considered. But their influence is negligible in a world with very ambitious climate protection measures. The emissions of district heating today depend on the heat mix fed into the networks (AGFW 2019). For 2050 it is assumed that the heat in heat networks is exclusively produced by large heat pumps, which are powered by $100 \%$ re- newable electricity. Heat accumulators in combination with heat pumps for a better coordination with renewable electricity generation make these assumptions plausible. As described in the previous section, synthetic methane is imported from North Africa. In North Africa, it is assumed that the synthetic methane is produced using electricity from renewable energy sources and that direct air capture (DAC) is used to gain $\mathrm{CO}_{2}$. Further upstream emissions are not taken into account.

Fig. 2 shows the annual $\mathrm{CO}_{2}$ emissions of the technologies in the building categories considered. From an environmental perspective, using heat networks with the current heat mix to supply existing MFH is the least attractive option, because this causes $\mathrm{CO}_{2}$ emissions nearly twice as high as supplying heat with a gas condensing boiler. Heat pumps are the technology with the lowest $\mathrm{CO}_{2}$ emissions despite the current power mix still including a 
large share of coal-fired electricity. This result is also found in the other building categories. The development in 2050 shows, that natural gas is the least attractive solution due to its $\mathrm{CO}_{2}$ emissions.

\section{Summary, conclusions, and outlook}

To achieve ambitious climate protection targets, fossil energy sources have to be almost completely replaced by renewable ones by 2050. This requires new technical solutions for the supply of energy. The distribution networks for electricity, gas, and heat play a prominent role in the necessary transformation based on the current annual investments of 5 billion euro in Germany, and the strong influence they have on the final energy prices for gas, electricity, and heat. This gives rise to the question, which distribution networks will still be required in the future. Another question is how the different kinds of distribution networks can be integrated more closely with each other using new technologies, such as electric heat pumps in heat networks, an issue which now falls under the topic of sector coupling.

From a regulatory viewpoint, gas and electricity distribution networks, as well as heat networks, are planned independently of each other at present. The tax burdens on the three energy sources also differ strongly, with the electricity price bearing the biggest burden per kWh compared to gas and heat. Nevertheless, because of their high efficiency, heat pumps are the most favorable solution in almost all building categories considered today and in 2050 under the assumptions made, with the exception of currently existing buildings, if (partial) refurbishment is disregarded. In this case, gas condensing boilers are the most cost-effective solution. The comparison assumed constant shares of network charges until 2050. Taking into account the decreasing gas demand and the increasing electricity demand the gas network charges would increase, and the electricity network charges decrease, making heat pumps an even more economically attractive option. From an environmental viewpoint, however, heat pumps currently already have the lowest $\mathrm{CO}_{2}$ emissions. In 2050 - assuming a decarbonized electricity sector - both heat pumps and a connection to the district heating network are the ecologically most attractive options.

Economically and environmentally, the most attractive option for residential end-users seems to be an electricity-based heat production in buildings, leading to the question of whether a parallel development of three different infrastructures is the best path for achieving GHG reduction targets or whether it would not be better to focus on the development of one or maybe two infrastructures. This raises the question, how much money should be invested in the natural gas distribution networks for supplying heat to buildings. Managing the transition phase in which the demand for gas falls sharply and, as a result, the specific gas network costs rise substantially, will be especially challenging for those households still dependent on gas supplies, gas suppliers and politicians. The design of this transformation process should be examined in greater depth in the future.

\section{Acknowledgments}

This work was financially supported by Fraunhofer Institute for Systems and Innovation Research ISI strategy fund in the context of the project "Development of a modelling concept for sector coupling at distribution network level" and by the Fraunhofer Cluster of Excellence Integrated Energy Systems CINES.

\section{References}

AGEB - Arbeitsgemeinschaft Energiebilanzen (2018): Auswertungstabellen zur Energiebilanz Deutschland. 1990 bis 2017. Available online at https:// ag-energiebilanzen.de/index.php?article_id=29\&fileName=ausw_30jul2018_ ov.pdf, last accessed on 05. 05.2020.

AGFW - Der Energieeffizienzverband für Wärme, Kälte und KWK e. V. (2019): Hauptbericht 2018. Available online at https://www.agfw.de/index. php?eID=tx_securedownloads $\& p=436 \& u=0 \& g=0 \& t=1588946561 \&$ hash $=e$ efab 9fde43fa0d35f496b2f7d1b9cd9e15fff7e\&file=fileadmin/user_upload/Zahlen_ und_Statistiken/Version_1_HB2018.pdf, last accessed on 07.05.2020.

BAFA - Bundesamt für Wirtschaft und Ausfuhrkontrolle (2019): Förderprogramm im Überblick. Available online at https://www.bafa.de/DE/Energie/ Heizen_mit_Erneuerbaren_Energien/Foerderprogramm_im_Ueberblick/ foerderprogramm_im_ueberblick_node.html, last accessed on 02.02.2020.

BCG - The Boston Consulting Group; prognos (2018): Klimapfade für Deutschland. Available online at https://image-src.bcg.com/Images/Klimapfade-fuer-

Deutschland_tcm108-181356.pdf, last accessed on 05.05.2020.

BDEW - Bundesverband der Energie- und Wasserwirtschaft e. V. (2017): 10 Thesen zur Sektorkopplung. Available online at https://www.bdew.de/ media/documents/Stn_20170427_Thesen-Sektorkopplung.pdf, last accessed on 05.05 .2020 .

BDEW - Bundesverband der Energie- und Wasserwirtschaft e. V. (2019): Wie heizt Deutschland? Studie zum Heizungsmarkt. Available online at https://www.bdew.de/media/documents/BDEW_Heizungsmarkt_ final_30.09.2019_3ihF1yL.pdf, last accessed on 20.01.2020.

BMU - Bundesministerium für Umwelt, Naturschutz und nukleare Sicherheit (2016): Klimaschutzplan 2050. Klimaschutzpolitische Grundsätze und Ziele der Bundesregierung. Berlin: BMU.

BNetzA - Bundesnetzagentur; Bundeskartellamt (2019): Monitoringbericht 2019. Bonn: Bundesnetzagentur für Elektrizität, Gas, Telekommunikation, Post und Eisenbahnen und Bundeskartellamt.

BWP - Bundesverband Wärmepumpe e. V. (2019): BWP Marktzahlen 2018. Nachhaltiges Wachstum mit Luft nach oben, deutliches Signal für die Politik. Available online at https://www.waermepumpe.de/presse/ pressemitteilungen/details/bwp-marktzahlen-2018-nachhaltiges-wachstummit-luft-nach-oben-deutliches-signal-fuer-die-politik/\#content, last accessed on 19.01.2020.

BWP - Bundesverband Wärmepumpe e. V. (2020): Wärmepumpen Förderratgeber 2020. Available online at https://www.waermepumpe.de/fileadmin/user_ upload/waermepumpe/07_Publikationen/Publikationen/BWP_Foerderung_ A6_2020.pdf, last accessed on 19.01.2020.

Clausen, Jens (2012): Kosten und Marktpotenziale ländlicher Wärmenetze. Hannover: Borderstep Institut für Innovation und Nachhaltigkeit gGmbH. Available online at https://www.borderstep.de/wp-content/uploads/2014/07/ClausenKosten_-laendliche_-Waermenetze-2012.pdf, last accessed on 30. 04. 2020. dena - Deutsche Energie-Agentur GmbH (2016): Der dena-Gebäudereport 2016. Statistiken und Analysen zur Energieeffizienz im Gebäudebestand. Berlin: dena. 
dena (2018): dena-Leitstudie Integrierte Energiewende. Impulse für die Gestaltung des Energiesystems bis 2050. Ergebnisbericht und Handlungsempfehlungen. Berlin: dena.

European Commission (2007): Commission Decision of 18 July 2007 establishing guidelines for the monitoring and reporting of $\mathrm{GHG}$ emissions pursuant to Directive 2003/87/EC of the European Parliament and of the Council. In: Official Journal of the European Union L 229, pp. 1-85.

Agora Energiewende; Frontier Economics (2017): PtG/PtL-Rechner Berechnungsmodell zur Ermittlung der Kosten von Power-to-Gas (Methan) und Powerto-Liquid. Modellversion 1.0. Available online at https://www.agoraenergiewende.de/veroeffentlichungen/ptgptl-rechner/, last accessed on 05. 05.2020.

Häupl, Peter et al. (2017): Lehrbuch der Bauphysik. Schall - Wärme - Feuchte Licht - Brand - Klima. Wiesbaden: Springer Vieweg.

Henning, Hans-Martin; Palzer, Andreas (2015): Was kostet die Energiewende? Wege zur Transformation des deutschen Energiesystems bis 2050. Freiburg: Fraunhofer ISE.

Hirzel, Simon (ed.) (2017): Energiekompendium. Stuttgart. FraunhoferVerlag.

KfW - Kreditanstalt für Wiederaufbau (2019): Energieeffizient Sanieren. Investitionszuschuss. Available online at https://www.kfw.de/inlandsfoerderung/ Privatpersonen/Bestandsimmobilien/Finanzierungsangebote/ Energieeffizient-Sanieren-Zuschuss-(430)/, last accessed on 12.12.2019.

KfW (2020): Effizient und umweltfreundlich heizen. Gefördert von der KfW. Available online at https://www.kfw.de/inlandsfoerderung/Privatpersonen/ Bestehende-Immobilie/Energieeffizient-sanieren/Heizung/\#16822577, last accessed on 02. 02.2020.

Miara, Marek; Günther, Danny; Kramer, Thomas; Oltersdorf, Thore; Wapler, Jeanette (2011): Wärmepumpen Effizienz. Messtechnische Untersuchung von Wärmepumpenanlagen zur Analyse und Bewertung der Effizienz im realen Betrieb. Freiburg: Fraunhofer ISE.

Öko-Institut; Fraunhofer ISI (2015): Klimaschutzszenario 2050.2. Endbericht. Available online at https://www.isi.fraunhofer.de/content/dam/isi/ dokumente/ccx/2015/Bericht_Runde_2.pdf, last accessed on 06.04.2020.

Scorza, Sophia; Pfeiffer, Johannes; Schmitt, Alex; Weissbart, Christoph (2018): Kurz zum Klima. Sektorkopplung. Ansätze und Implikationen der Dekarbonisierung des Energiesystems. In: ifo Schnelldienst 71 (10), pp. 49-53.

UBA - Umweltbundesamt (2019): Strom- und Wärmeversorgung in Zahlen. Available online at https://www.umweltbundesamt.de/themen/klima-energie/ energieversorgung/strom-waermeversorgung-in-zahlen?sprungmarke=Strom mix\#Strommix, last accessed on 26. 01.2020.

UNFCCC - United Nations Framework Convention on Climate Change (2015): Paris Agreement. United Nations. Available online at https://unfccc.int/sites/ default/files/english_paris_agreement.pdf, last accessed on 17.02.2020.

Viebahn, Peter et al. (2018): Technologien für die Energiewende. Teilbericht 2 an das Bundesministerium für Wirtschaft und Energie (BMWi). Available online at https://epub.wupperinst.org/frontdoor/deliver/index/docld/7083/file/ WR13-2.pdf, last accessed on 05. 05.2020.

Wachsmuth, Jakob et al. (2019): Roadmap Gas für die Energiewende. Nachhaltiger Klimabeitrag des Gassektors. Dessau-Roßlau: Umweltbundesamt.

WIBERA - WIBERA Wirtschaftsberatung AG (2017): Fernwärmepreisübersicht. Kurzumfrage. Available online at https://www.pwc.de/de/energiewirtschaft/ ergebnisse-der-agfw-wibera-preisumfrage-10-2017.pdf, last accessed on 20.01.20.
Wietschel, Martin et al. (2018 a): Integration erneuerbarer Energien durch Sektorkopplung. Teilvorhaben 2. Analyse zu technischen Sektorkopplungsoptionen. Endbericht. Dessau-Roßlau: Umweltbundesamt.

Wietschel, Martin et al. (2018 b): Sektorkopplung. Definition, Chancen und Herausforderungen. Diskussionspapier im Rahmen des Kopernikus-Projekt „Systemintegration“. Karlsruhe: Fraunhofer ISI.
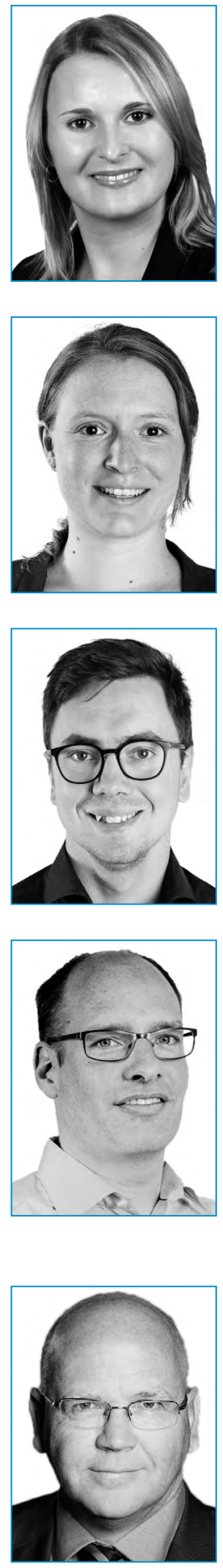

\section{STELLA OBERLE}

has worked at Fraunhofer ISI in the Competence Center Energy Technology and Energy Systems since 2018. Her focus is on sector coupling on a distribution network level and on the gas distribution network. She has a double master's degree (InnoEnergy Master School) in Energy Technologies and in Energy Engineering and Management.

\section{JUDITH STUTE}

has been a researcher at Fraunhofer ISI in the Competence Center Energy Technology and Energy Systems since 2018. Her work focus is on electricity distribution grids. She holds a master's degree in Electrical Engineering with a specialization in electrical power engineering from RWTH Aachen University.

\section{MARKUS FRITZ}

has worked as a researcher in the Competence Center Energy Technology and Energy Systems at the Fraunhofer Institute for Systems and Innovation Research ISI in Karlsruhe since 2018. His current work focus is on waste heat utilization and energy efficiency in buildings. He has a master's degree in environmental engineering.

\section{DR. MARIAN KLOBASA}

Dr. Marian Klobasa has been the coordinator of the Business Unit Demand Response and Smart Grids in the Competence Center Energy Technology and Energy Systems since 2014. He has worked for the Fraunhofer Institute for Systems and Innovation Research (ISI) since September 2002. He studied mechanical engineering at Karlsruhe University and received a doctoral degree at the ETH Zurich in 2007.

\section{PROF. DR. MARTIN WIETSCHEL}

Prof. Dr. Martin Wietschel was the Deputy Head of the Competence Center Energy Technology and Energy Systems at the Fraunhofer Institute for Systems and Innovation Research ISI from January 2012 until February 2020, when he became the Head. Since 2008 he has also been an adjunct professor at the Karlsruhe Institute of Technology (KIT). He studied Industrial Engineering and Management. 


\section{The convergence of electricity and digitalization in the Netherlands}

\section{Data governance as an emerging policy issue}

Romy Dekker, Rathenau Instituut, Anna van Saksenlaan 51, 2593 HW Den Haag (r.dekker@rathenau.nl)

Rinie van Est, Rathenau Instituut (q.vanest@rathenau.nl)

This paper explores the convergence of electricity and digitalization in the Netherlands. Based on the Advocacy Coalition Framework, we first show how the Paris Agreement on global warming in 2015 has led to a new renewable energy policy paradigm, in which digitalization plays a key enabling role. We will then show that the far-reaching convergence of electricity and digitalization pursued by European and Dutch policy makers will raise new policy issues. The core challenge is adequate energy data governance. Digitalization also raises policy issues in the areas of safety, consumer protection, democratic control, and equal distribution of costs and benefits in a digitized energy system. As the transition to a sustainable energy system must take place rapidly and energy data are expected to play a crucial role in achieving this, these issues are urgent.

\section{Die Konvergenz von Elektrizität und Digitalisierung in den Niederlanden \\ Data Governance als neues politisches Thema}

Dieser Artikel befasst sich mit der Konvergenz von Elektrizität und Digitalisierung in den Niederlanden. Anhand des Advocacy Coalition Framework zeigen wir zunächst, dass das Pariser Abkommen zur globalen Erwärmung im Jahr 2015 zu einem neuen Paradigma der Politik für erneuerbare Energien geführt hat, bei dem Digitalisierung eine zentrale Rolle spielt. Darüber hinaus werden wir zeigen, dass die weitreichende Konvergenz von Elektrizität und Digitalisierung, die von europäischen und niederländischen Politikern angestrebt wird, neue politische Fragen aufwerfen wird. Die zentrale Herausforderung ist ein entsprechendes Energiedatenmanagement. Darüber hinaus wirft die Digitalisierung auch politische Fragen im Bereich Sicherheit, Verbraucherschutz, demokratische Kontrolle und die gleichmäßige Verteilung von Kosten und Nutzen in einem digitalisierten Energiesystem auf. Da der Übergang zu

This is an article distributed under the terms of the Creative Commons Attribution License CCBY 4.0 (https://creativecommons.org/licenses/by/4.0/)

https://doi.org/10.14512/tatup.29.2.31

Submitted: 20.02.2020. Peer reviewed. Accepted: 15. 05.2020 einem nachhaltigen Energiesystem rasch erfolgen muss und Energiedaten hierfür voraussichtlich eine entscheidende Rolle spielen werden, sind diese Fragen dringend.

Keywords: global warming, digitalization, energy policy, data governance

In the Netherlands the digitalization of the electricity sector is in full swing: from the almost completed roll out of the smart meter to mushrooming energy platforms (Kloppenburg and Boekelo 2019). Current developments in the ICT-sector - advancements in data, analytics and connectivity - and the ongoing decarbonization of energy systems are expected to accelerate the convergence of digitalization and energy (IEA 2017). The Paris agreement of 2015 and the Dutch policy goals to come to a $49 \% \mathrm{CO}_{2}$ reduction by 2030 and a $95 \% \mathrm{CO}_{2}$ reduction by 2050, drive the emergence of large numbers of intermittent and often distributed energy resources (DER). As a result, electricity grids need to become smarter and in this way the convergence of electricity and digitalization is stimulated (Milchram et al. 2018; Tagliapietra et al. 2019). These rapid technological changes also require regulatory institutional changes (Koirala et al. 2018).

In this paper we explore the policy challenges associated with this scenario of far-reaching digitalization of the electricity sector pursued by Dutch policymakers. We take a policy perspective because public policies are major drivers of the desired sustainable energy transition (Markard et al. 2016). We use the Advocacy Coalition Framework (ACF) (Sabatier and Jenkins-Smith 1993) to study how global warming and climate policy are leading to major changes in energy policy and to gain insight into the policy challenges associated with the digitization of the electricity system. To do that the Dutch energy policy is, in line with ACF, conceptualized as a policy belief system. In doing so the paper contributes to policy process theories and, since policy changes are a crucial part of larger socio-technical transi- 
tions, holds relevance for sustainable transition studies (Kern and Howlett 2009; Markard et al. 2016).

Our policy analysis covers a long period of about 25 years: from 1995 to 2019. Our research is based on various relevant policy documents, such as the national energy policy reports of the Ministry of Economic Affairs and Climate which appear every four years. These energy reports look back at developments in recent years and determine the energy policy for the years to come. In addition, we analyzed the electricity law of 1998 and the Independent Network Management Act of 2006. Moreover, to verify our analysis, we organized several meetings with policy makers from the department of Economic Affairs and Climate, social scientists and experts from the energy sector to discuss our work.

The paper is structured as follows: in the following section we introduce the ACF. Next, we describe the influence of global warming and climate policy on energy policy. We will show that digitalization of the electricity sector has become a new policy core belief. We further analyze how the convergence of electricity with digitalization raises new policy issues. The conclusion discusses the implications of the analysis and highlights data governance as an emerging policy concern.

\section{The Advocacy Coalition Framework: a short description}

The ACF aims to understand the process of policy change over time (Sabatier and Jenkins-Smith 1993). It assumes that a focus on 'policy subsystems' - that is, those actors from a variety of public and private organizations who are actively concerned with a policy problem or issue - is a useful way to think about policy change over a period of more than a decade. Another basic premise of the ACF is that public policies (or programs) incorporate implicit theories about how to achieve their objectives and can thus be conceptualized in the same manner as belief systems, that is, as a set of value priorities, perceptions of the magnitude of the problem and causal assumptions about how to solve them.

According to the ACF, policy change over time is a function of three sets of processes. The first concerns the interaction of competing advocacy coalitions, that consist of actors who share a set of basic beliefs, within a subsystem. The second set of processes concerns changes external to the subsystem, like change of government or in socioeconomic or technological conditions. The third set involves the effects of stable system parameters, such as constitutional rules or the basic attributes of the problem area, on the constraints and resources of the various subsystem actors.

The ACF conceptualizes policy by means of policy belief systems and related policy change by means of changes in policy belief systems. The ACF distinguishes three hierarchical levels of beliefs: (1) Deep core beliefs refer to fundamental assumptions and worldviews and are very difficult to change. At the second level, policy core beliefs are about basic positions in a policy subsystem, e. g. with regard to the role of the state or the prominence and understanding of the policy issue. (2) Policy core beliefs encompass an entire policy subsystem and are hypothesized to be relatively stable over periods of a decade or more. (3) Secondary beliefs serve as premises for specific policies to be implemented or measures to be taken within a specific subsystem.

The ACF distinguishes between minor change as a result of changes in secondary beliefs and major policy change as a consequence of shifting core beliefs. According to the ACF, core beliefs will seldom change voluntarily (Sabatier and Weible 2007). Major external shocks, like the oil crisis or the Chernobyl nuclear disaster, are needed to cause major policy change. A major policy change can even result in a so-called policy paradigm shift (Hall 1993). In a policy paradigm shift, changes occur on each of the three levels of the policy belief system although certain dimensions of the old paradigm will remain after the shift (Salas Girones et al. 2019).

\section{Paris Agreement leads to major policy changes}

\section{Tracking changes in the energy policy belief systems}

In this section we analyze how a major change in climate policy, in particular the Paris Agreement in 2015, influenced Dutch energy policy. In terms of the ACF the Paris Agreement can be seen as a major external development which requires adjustment of energy policy and the energy system. The nation's ambition to come to a $49 \% \mathrm{CO}_{2}$ reduction by 2030 , has led to the Dutch government's decision to phase out fossil fuels and develop a cleaner, decentralized energy system, and thus new ways of producing and consuming (renewable) energy.

This section describes that the Paris Agreement has led to major energy policy changes. We use the ACF's three hierarchical levels of the energy policy belief system - deep core beliefs, policy core beliefs and secondary policy beliefs - to show that. We will describe the Dutch energy policy before and after the Paris Agreement. Because we see changes at both the deep core and policy core beliefs level, we conclude that the Paris climate treaty led to a paradigm shift in energy policy. The policy paradigm which characterized the Dutch energy policy between 1998 up to 2015 is named fossil energy market policy paradigm. The paradigm from 2015 onwards is called the renewable energy market policy paradigm (see table 1).

\section{Deep core beliefs}

Over the last two decades, affordability, reliability and clean energy have been the main goals or deep core beliefs of the Dutch energy policy (TK 1995; EZ 2008; EZLI 2011). These deep core beliefs should be achieved at the same time and are often referred to as a 'trilemma' (Edens 2017). Affordability refers to an energy system that is economically efficient and reliability relates to security of supply (EZ 2008). With a reliability 


\begin{tabular}{|l|l|l|}
\hline \multicolumn{2}{|l|}{ Fossil energy market policy paradigm (1998-2015) } \\
\hline Deep core beliefs & $\begin{array}{l}\text { Affordable } \\
\text { Reliable } \\
\text { (Somewhat) Clean (20\% in 2020) }\end{array}$ & $\begin{array}{l}\text { Affordable } \\
\text { Reliable } \\
\text { (Very) Clean (95\% in 2050) } \\
\text { Safe }\end{array}$ \\
\hline Policy core beliefs & $\begin{array}{l}\text { Liberalization } \\
\text { Privatization } \\
\text { Clean and efficient energy }\end{array}$ & $\begin{array}{l}\text { Liberalization } \\
\text { Privatization } \\
\text { Clean and efficient energy } \\
\text { Digitalization }\end{array}$ \\
\hline Secondary beliefs & $\begin{array}{l}\text { Promotion of clean/efficient energy } \\
\text { Electricity grid } \\
\text { Energy market design } \\
\text { Consumer protection framework }\end{array}$ & $\begin{array}{l}\text { Promotion of clean/efficient energy } \\
\text { Electricity grid } \\
\text { Energy market design } \\
\text { Consumer protection framework }\end{array}$ \\
\hline
\end{tabular}

Tab.1: Belief system change for Dutch energy policy.

of $99.994 \%$ of the Dutch electricity grid, it can be said that the Dutch energy system was successful in obtaining the deep core belief of reliability. Clean energy was defined as an energy supply with the highest possible environmental quality (EZ 2008). Even though the deep core of 'clean' has been pursued through various policies and goals over the years, in 2018, $90 \%$ of Dutch electricity was still provided by centralized coal and natural gas based power plants (CBS 2019). Consequently, it may be concluded that cleanliness was not a priority, as opposed to affordability and reliability. We refer to the policy paradigm during this time span as the fossil energy market policy paradigm.

After the Paris Agreement the political weight and policy interpretation of the deep core belief 'clean' changed drastically. To combat global warming, and in line with the Paris agreement of 2015, the Dutch government expressed in 2016 the ambition to strive for a low carbon energy supply that is reliable, affordable and, for the first time mentioned, safe (EZK 2016). Thus, even though the deep core belief of 'clean' remains the same word, its meaning and priority changes substantially under the influence of global warming.

\section{The Paris Agreement in 2015 has led to a paradigm shift in the Dutch energy policy.}

Dutch energy policy aims for $70 \%$ of electricity to be provided by renewable energy resources in 2030 (EZK 2019). To facilitate this, the Dutch energy system must undergo a drastic change from a centralized, fossil energy system to a more distributed, renewable energy system. Renewable energy resources are often intermittent and implemented at the distribution level, making it more complex to secure the reliability of the grid.
As a consequence, the electricity grid needs to be expanded by putting more cables in the ground. This is a very costly activity and in the Netherlands the costs for expanding the network are shared by all electricity consumers. All this leads to a greater challenge to continue safeguarding the reliability and affordability of the Dutch energy system.

We argue that the novel and radical interpretation of the deep core belief 'clean' has led to a new policy paradigm, which we name the renewable energy market policy paradigm. Below we investigate to what extent the policy core beliefs and secondary beliefs of the Dutch energy policy have changed.

\section{Policy core beliefs}

To strive for a clean, affordable and reliable electricity system, liberalization, privatization and clean and efficient energy formed the policy core beliefs of the Dutch energy policy to 2015. In the Netherlands, fundamental choices for liberalization and privatization respectively, are laid down in the Electricity Act of 1998 and the Independent Network Management Act of 2006. To safeguard the reliability, the responsibility for grid management was placed in public hands. In addition, market mechanisms were introduced on the supply side to secure the affordability of energy.

After the Paris Agreement the existing policy core beliefs have remained the same. The Dutch government expresses its belief that the transition towards a 'very' clean energy supply can be achieved with a liberalized and privatized market and by continuing stimulating renewable energy and energy efficiency (EZK 2016). However, prioritizing 'clean' makes it more difficult to secure the affordability and reliability of the energy system. In line with the European Commission (EC 2019), the Dutch Ministry of Economic Affairs and Climate (EZK 2018) expects that digitalization can enable the transition towards a clean, affordable and reliable energy system. So digitalization has been added as a new policy core belief within the Dutch renewable energy market policy paradigm. 
Driven by these policy changes, it is expected that central, fossil-based power plants are going to be replaced by large numbers of intermittent and often distributed, renewable energy sources. In certain parts of the Netherlands, the rapidly growing demand for transport capacity is already causing a queue of requests that prevents renewable energy sources such as wind and solar to be connected to the grid (EZK 2019). The demand for electricity is also increasing because of the electrification of other sectors such as heating and transport. As a result, the distribution network is becoming more complex to manage (Koirala et al. 2018; Lavrijssen 2017).

Besides putting more cables into the ground, the Dutch government advocates the use of digitalization to manage the grid in
TSOs but also DSOs need to become active managers of smart electricity grids. To facilitate this, adjustments need to be made at the secondary belief category of electricity grids to make it possible for DSOs to fulfill this role (RVO 2015).

Smart grid technologies facilitate the integration of large numbers of distributed generation by automatically balancing supply and demand and reducing electricity peaks. Smart grid technologies can refer to different subsystems within the energy system such as smart meter systems, smart home energy management systems, demand side-response, household storage, and the integration of electric-vehicles (Milchram et al. 2018). On the one hand, smart grids can help to deal with the increased complexity. On the other hand, since they increase the diversity

\section{Prioritizing 'clean' energy makes it more difficult to secure the affordability and reliability of the energy system.}

a smarter way (EZK 2018). More and more components within the energy system are already equipped with digital technologies that enable the collection and analysis of large amounts of data to improve the reliability and affordability of the energy system. In this way, digitalization could "help with better network management, assisting with the renewable generation intermittency problem, allowing more effective network monitoring and more efficient network operation" (Küfeoglu et al. 2019, p. 1).

\section{Secondary beliefs}

To implement the policy core beliefs of liberalization, privatization and clean and efficient energy, there are four main secondary belief categories covering the most important policy instruments. The categories relate to: 1) guidelines for electricity grid management, planning and operation, 2) the energy market design in which roles and responsibilities, non-discriminatory access for third parties and guidelines for a level-playing field are defined, 3 ) the promotion of clean energy to support energy efficiency measurements such as the roll out of the smart meter and subsidies for renewable energy and 4) the establishment of a consumer protection framework such as for price monitoring and monitoring of accessible information for consumers. We describe below how, as a result of the desired steep rise of renewable energy resources, the other three secondary beliefs might change and what role digitalization plays in it.

The new energy system should be "less polluting, more distributed and altogether smarter" (Edens 2017, p. 134). In the 'old' situation, demand for electricity was leading and power stations were adjusted accordingly. The Dutch electricity law held the transmission system operator (TSO) responsible to ensure that at all times the electricity fed into the network is the same as the electricity extracted from the network. In this situation the distribution system operator (DSO) was mainly responsible for 'burying copper in the ground'. In the new situation not only of actors and add new roles, smart grids also add extra complexity with regard to organizing the electricity market. As a result, new questions on data property and market access rights are raised (Milchram et al. 2018). Action is already being taken in the form of a legal regime for data access and data management that was proposed by the European Commission in the Electricity Directive and adopted by the European Parliament and Council in 2019 (EC 2019).

Access and control over data could also enable citizens and communities to play a more active role in the energy system. In combination with renewable energy sources such as solar panels, consumers can become prosumers that participate in the energy transition through online platforms (Kloppenburg and Boekelo 2019). Involvement of citizens and communities is even seen as one of the biggest challenges of the future energy system, a challenge where digitalization can help (Koirala et al. 2018). However, the changing role of citizens in the energy system also implies that changes are necessary at the secondary belief level of the consumer protection framework. Below we will highlight some challenges that relate to this.

\section{Policy issues related to convergence of electricity with digitization}

The former section showed that policy makers see digitalization as crucial for enabling the sustainable energy transition. The convergence of digitalization with electricity not only creates opportunities. Digital technologies such as robotics, big data, AI and digital platforms evoke a wide range of social issues (Kool et al. 2017, Royakkers et al. 2018). Important public values and human rights could be at stake such as privacy, equal treatment, autonomy and control over technology. It is increasingly acknowledged that the digitization of the Dutch energy 
system raises similar issues (Hollander et al. 2017; RLI 2018; Milchram et al. 2018; Kloppenburg and Boekelo 2019). If such concerns are not properly addressed they can form serious barriers for the development and adoption of digital technologies in the energy system.

This section analyses some policy issues pertaining to digitization of the electricity system by investigating the significance of digitization on various elements of the energy policy belief system. Based on academic literature research, we identify the following issues: digital security, data governance, equal distribution of costs and benefits and control as well as supervision of digitalization.

\section{A digital secure infrastructure}

The energy system is a critical infrastructure that is of great societal importance. In addition, certain functions and sectors, such as heating and transport, will become even more interconnected and interdependent. Given the crucial role of data for the energy market, digital security is a concern for all those sectors. Digitization not only makes the energy system more flexible, but also more vulnerable: for software errors, but also for unpredictable behavior by algorithms, and for cyberattacks (RLI 2018; Munnichs et al. 2017). The 'new' energy system is expected to consist of "both cyber and physical assets that are tightly integrated, and all of these assets must be protected" (Pérez-Arriaga and Knittel 2016, p. 67). Therefore, the 'new' deep core belief of safe should also be interpreted as digitally safe and the secondary beliefs related to the electricity grid must be equipped with a cybersecurity component.

\section{Data governance as a new core function}

The major policy change resulting from the convergence of digitalization and clean energy is putting data governance on the policy agenda. Data governance is becoming a core function for the renewable energy system (Pérez-Arriaga and Knittel 2016). In fact, data governance cannot be separated from digitalization as a policy core belief and should therefore also be integrated in all secondary belief categories. Below we highlight some of the policy challenges related to data governance.

The rationale for data governance is often unclear and remains vague by calling for "a fair competition for data" (Ducuing 2019 , p. 9). The notion of data governance should therefore be interpreted more concretely. In line with this vision, the Dutch Authority for Consumers and Markets (ACM) argues that the current data governance model is not sufficient to facilitate the energy transition since it is still based on the situation in which meter data was requested once a year and only market roles recognized by law had access to energy data. Therefore, the ACM advocates for energy data governance that is affordable, reliable, safe, protects the privacy of consumers and ensures that they have control over their data (ACM 2019). Additionally, we propose that the aforementioned social issues related to digitalization should also be integrated in the energy data governance model. This is currently not the case.
The Electricity Directive proposes a new market design that contains a legal framework for data governance with accompanying secondary beliefs such as that "Member States shall ensure that all eligible parties have non-discriminatory access to data under clear and equal terms, in accordance with the relevant data protection rules." (European Parliament and Council of the European Union, art. 23.2). These secondary beliefs related to the category 'electricity market design' give substance to the policy core of liberalization and privatization which are integrated into the energy data layer.

The Electricity Directive also states that energy data is to "include metering and consumption data as well as data required for customer switching, demand response and other services" (ibid). However, according to Ducuing (2019, p. 9): "it remains unclear what 'other services' concretely consist of". Data generation by most DERs, such as rooftop solar panels or electric cars, is taking place 'behind the meter' and are "hence not covered by traditional energy regulation" (Tagliapietra et al. 2019, p. 952). In addition, the use of these types of non-regulated data raises various issues in the field of autonomy, privacy, cybersecurity and equal treatment.

The Electricity Directive refers to the role of the data management operator (EC 2019). Given the expectation that due to the energy transition, the system task of DSOs will become increasingly important and that access to data is crucial for this, Pérez-Arriaga and Knittel (2016) argue in favor of combining the management of the physical network with the management of data. These scholars also state that non-innovative DSOs risk losing knowledge in the long term to efficiently manage the highly digitized electricity grid of the future (Enerquire 2018). In that case a takeover by "dominant tech companies, becoming operator of the digital work in the country distribution platform" could become an option (Tagliapietra et al. 2019, p. 951). Such an option directly raises the issue of how public governance of such large tech companies should be shaped in a democratic fashion. The dependence of democratic government on technical expertise and companies can also play a role at the local level. Milchram et al. (2018, p. 1253) state that "greater reliance on novel technologies in smart grids, which require more special knowledge, leads to perceptions that knowledge concentrated at private corporations is seen as source of power over municipalities".

\section{Promotion of sustainable energy: equal distribution of costs and benefits}

Clean energy and digitalization can undermine the justice of the current energy system in various ways. Roles, responsibilities, rights and obligations that were previously fair can in the (near) future contribute to an unfair distribution of costs and benefits. Purchasing solar panels or setting up a local energy community requires financial as well as social and technical skills. Even though prosumers and local energy communities can benefit from their investments in renewable energy, it is the general public who has to pay for the infrastructure that makes those investments possible. Moreover, trading of energy by communities 
is likely to put more strains on the grid in this way endangering its affordability and reliability (Kloppenburg and Boekelo 2019). On the other hand, prosumers and communities can also deliver the flexibility that is needed for matching energy supply and demand. Whether someone has the ability to be flexible depends on one's flexibility capital and other dimensions such as age or levels of digital inclusion. These flexibility conditions raise questions about 'flexibility justice' (Powells and Fell 2019). It is therefore important to find a fair balance between the money that active consumers earn and the system value of the services, such as flexibility, that they offer (Pérez-Arriaga and Knittel 2016).

\section{Consumer protection: control and supervision}

The promise of digitalization and smart grids in particular, is that they can contribute to more equitable and democratic energy systems. Smart grids enable the shift towards more small scale electricity generation and empower citizens to play a more active role. Milchram et al. (2018) wonder whether smart grids actually give 'power to the people'. Whether citizens will be able to benefit from the new opportunities will likely depend on their ability to invest and their (required) level of knowledge.

There is more to this, in recent decades the internet has become a Utopia for mass surveillance, mass behavioral experiments and, profiling and manipulating people on a large scale (Lanier 2018; Zuboff 2019). The internet is putting considerable pressure on people's privacy and autonomy. For example, Google's Nest smart thermostat can be "transformed into a spy that can not only report on the routines of the inhabitants of a certain home or office, but also on their cyber activities and provide a backdoor to their local network which could go unnoticed." (Hernandez et al. 2014, p. 7).

Whether smart energy systems strengthen or weaken people's autonomy and enhance the democratic controllability of the energy system, depends on the extent to which users have insight into and control over those algorithmic systems. According to the Dutch Authority for Consumers and Markets, the current situation is unclear and a new data governance model should clearly facilitate this right (ACM 2019). Therefore, it must be

\section{The core challenge is adequate energy data governance.}

clarified how and on what basis, automatic decisions are made and who is responsible for the decisions taken (Raad van State 2018). It is also important that supervisors remain able to control such processes (Jong et al. 2019). Also mushrooming energy platforms cause new opacities, dependencies and uncertainties for both consumers and prosumers (Kloppenburg and Boekelo 2019). From the point of view of autonomy, it is also crucial that energy consumers can make well-informed and optimal choices in a future intelligent energy system (Lavrijssen 2017).

\section{Conclusion}

The Paris Agreement in 2015 has led to a paradigm shift in the Dutch energy policy: from a fossil to a renewable energy market policy paradigm. The Paris climate treaty led to a reinforcement of the importance of the deep core belief 'clean' and the need for a shift towards a renewable energy system. Since policy makers see digitalization as crucial for enabling the sustainable energy transition, digitalization has become an important extra policy core belief of the renewable energy market policy paradigm. At the level of the secondary beliefs the categories seem to remain the same but the interpretation thereof will be strongly influenced by digitalization.

We showed that the far-reaching convergence of electricity and digitalization pursued by European and Dutch policy makers will raise new policy issues. The core challenge is adequate energy data governance. Digitalization also raises policy issues in the field of safety, consumer protection, democratic control and the equal distribution of costs and benefits in a digitized energy system. The speed with which the sustainable energy transition must take place and the foreseen crucial role of energy data to enable that transition, make these policy challenges urgent.

\section{References}

ACM - Autoriteit Consument en Markt (2019): Visiedocument datagovernance energie. Den Haag: Autoriteit Consument en Markt.

CBS - Centraal Bureau Statistiek (2019): Energieverbruik gedaald in 2018. Available online at https://www.cbs.nl/nl-nl/nieuws/2019/16/ energieverbruik-gedaald-in-2018, last accessed on 12.04.2020.

Ducuing, Charlotte (2019): Data as infrastructure? A study of data sharing legal regimes. In: Competition and Regulation in Network Industries, online first, p. 19

EC - European Commission (2019): Clean Energy for All Europeans. Brussels: European Commission.

Edens, Marga (2017): Public value tensions for Dutch DSOs in times of energy transition. A legal approach. In: Competition and Regulation in Network Industries, 18 (1-2), pp. 132-149.

European Parliament; Council of the European Union (2019): Directive (EU) 2019/944 on common rules for the internal market for electricity and amending Directive 2012/27/EU. In: Official Journal of the European Union L 158, pp. 125-199.

EZ - Economische Zaken (2008): Energierapport 2008. Den Haag: Ministerie van Economische Zaken.

EZK - Economische Zaken en Klimaat (2016): Energieagenda. Naar een $\mathrm{CO}_{2}-$ arme energievoorziening. Den Haag: Ministerie van Economische Zaken en Klimaat.

EZK (2018): Nederlandse Digitaliseringsstrategie. Nederland digitaal. Hier kan het. Hier gebeurt het. Den Haag: Ministerie van Economische Zaken en Klimaat.

EZK (2019): Gevolgen van het gebrek aan netcapaciteit voor duurzame elektriciteitsprojecten. Den Haag: Ministerie van Economische Zaken.

EZLI - Economische Zaken, Landbouw en Innovatie (2011): Energierapport 2011. Den Haag: Ministerie van Economische Zaken, Landbouw \& Innovatie. 
Hall, Peter (1993): Policy paradigm, social learning, and the state. The case of economic policy making in Britain. In: Comparative Politics 25 (3), pp. 275-296.

Hernandez, Grant; Arias, Orlando; Buentello, Daniel; Jin, Yier (2014): Smart nest thermostat. A smart spy in your home. Available online at https:// www.blackhat.com/docs/us-14/materials/us-14-Jin-Smart-Nest-ThermostatA-Smart-Spy-In-Your-Home-WP.pdf, last accessed on 07.05.2020.

Hollander, Guus de; Vonk, Marijke; Snellen, Daniëlle; Hiddo Huitzing (2017): Mobiliteit en elektriciteit in het digitale tijdperk. Publieke waarden onder spanning. Den Haag: Planbureau voor de Leefomgeving.

Jong, Roos de; Kool, Linda; Est, Rinie van (2019): This is how we put Al into practice based on European Values. Den Haag: Rathenau Instituut.

Kern, Florian; Howlett, Michael (2009): Implementing transition management as policy reforms. A case study of the Dutch energy sector. In: Policy Sciences 42 (4), pp. 391-408.

Kloppenburg, Sanneke; Boekelo, Marten (2019): Digital platforms and the future of energy provisioning. Promises and perils for the next phase of the energy transition. In: Energy Research \& Social Science 49, pp. 68-73.

Koirala, Binod; Oost, Ellen van; Windt, Henny van de (2018): Community energy storage. A responsible innovation towards a sustainable energy system? In: Applied energy 231, pp. 570-585.

Kool, Linda; Timmer, Jelte; Royakkers, Lambèr; Est, Rinie van (2017): Urgent upgrade. Protect public values in our digitized society. Den Haag: Rathenau Instituut.

Küfeoglu, Sinan; Gaomin, Liu; Anaya, Karim; Pollitt, Michael (2019). Digitalisation and new business models in energy sector. Energy Policy Research Group, University of Cambridge, working paper 1920. Available online at https://www.eprg.group.cam.ac.uk/wp-content/uploads/2019/06/1920-Text. pdf, last accessed on 07.05.2020.

Lanier, Jaron (2018): Tien argumenten om je sociale media-accounts nu meteen te verwijderen. Amsterdam: Uitgeverij Business Contact.

Lavrijssen, Saskia (2017): Power to the energy consumers. In: European Energy and Environmental Law Review 26 (6), pp. 172-187.

Markard, Jochen; Suter, Marco; Ingold, Karin (2016): Socio-technical transitions and policy change. Advocacy coalitions in Swiss energy policy. In: Environmental Innovation and Societal Transitions 18, pp. 215-237.

Milchram, Christine; Hillerbrand, Rafaela; Kaa, Geerten van de; Doorn, Neelke; Künneke, Rolf (2018): Energy justice and smart grid systems. Evidence from the Netherlands and the United Kingdom. In: Applied Energy 229, pp. 1244-1259.

Munnichs, Geert, Kouw, Matthijs; Kool, Linda (2017): Een nooit gelopen race. Over cyberdreigingen en versterking van weerbaarheid. Den Haag: Rathenau Instituut.

Pérez-Arriaga, Ignacio; Knittel, Christopher (2016): Utility of the future. An MIT Energy Initiative response to an industry in transition. Cambridge, MA: MIT.

Powells, Gareth; Fell, Michael (2019): Flexibility capital and flexibility justice in smart energy systems. In: Energy Research \& Social Science 54, pp. 56-59.

Raad van State (2018): Ongevraagd advies over de effecten van digitalisering voor de rechtsstatelijke verhoudingen. Den Haag: Raad van State.

Royakkers, Lambèr; Timmer, Jelte; Kool, Linda; van Est, Rinie (2018): Societal and ethical issues of digitization. In: Ethics and Information Technology 20 (2), pp. 127-142. DOI: 10.1007/s10676-018-9452-x.
RVO - Rijksdienst voor Ondernemend Nederland (2015): Innovatieprogramma Intelligente Netten. Position paper kennis- en leertraject - Thema weten regelgeving. Utrecht: Rijksdienst voor Ondernemend Nederland.

RLI - Raad van Leefomgeving en Infrastructuur (2018): Stroomvoorziening onder digitale spanning. Den Haag: Raad voor de leefomgeving en infrastructuur.

Sabatier, Paul; Jenkins-Smith, Hank (1993): Policy change and learning. An advocacy coalition approach. Boulder: Westview.

Sabatier, Paul; Weible, Christopher (2007): The advocacy coalition framework. An assessment. In: Paul Sabatier (ed.): Theories of the policy process. Boulder: Westview, pp.189-220.

Salas Girones, Edgar; Est, Rinie van; Verbong, Geert (2019): Transforming mobility. The Dutch smart mobility policy as an example of a transformative STI policy. In: Science and Public Policy 46 (6), pp. 820-833.

Tagliapietra, Simone; Zachmann, Georg; Edenhofer, Ottmar; Glachant, JeanMichel; Linares, Pedro; Loeschel, Andreas (2019): The European Union energy transition. Key priorities for the next five years. In: Energy Policy 132, pp. 950-954.

TK - Tweede Kamer (1995): Derde energy memorandum. Den Haag: Ministerie van Economische Zaken.

Zuboff, Shoshana (2019): The age of surveillance capitalism. The fight for a human future at the new frontier of power. London: Profile Books.

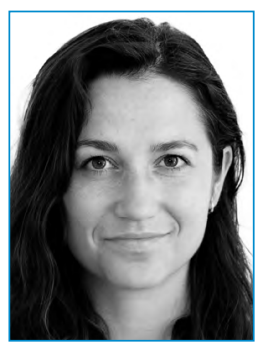

\section{ROMY DEKKER}

has been working as a researcher at the Rathenau Institute since 2018. She is currently working on a project about the convergence of digitalization and clean energy. Romy completed a Bachelor and Masters in Cultural Anthropology and Development Sociology.

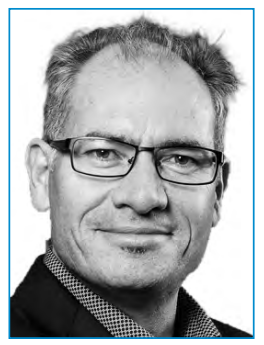

PROF.DR.IR. RINIE VAN EST

coordinates research within the theme Digital Society. He is involved in the field of energy transition and digital transition. He joined the Rathenau Instituut in 1997. Since 2000, he also works parttime at the Eindhoven University of Technology, where he currently holds the chair of Technology Assessment and Governance. 


\title{
Sector coupling \\ of renewable energy in an experimental setting
}

\author{
Findings from a smart energy pilot project in Austria
}

Michael Ornetzeder, Institute of Technology Assessment, Austrian Academy of Sciences, Apostelgasse 23, 1030 Vienna (michael.ornetzeder@oeaw.ac.at)
(D) https://orcid.org/0000-0003-3956-7090
Tanja Sinozic, Institute of Technology Assessment, Austrian Academy of Sciences (tanja.sinozic@oeaw.ac.at) (D) https://orcid.org/0000-0002-1070-1340

The integration of previously unconnected sectors of the energy system is considered one of the most important strategies for reducing $\mathrm{CO}_{2}$ emissions. Many studies on technological innovations that deal with the transition to a sustainable energy system focus on innovation niches as a favorable environment within which new solutions can be tested and made ready for the market. This paper examines how protection in such a niche, in combination with organizational path dependency, supports the integration of renewable energy in residential buildings. The results presented are based on a case study on the integration of the electricity, heat, and gas sectors in a housing pilot project, in which local energy needs are met and electricity is fed into the grid in a flexible way. Our findings indicate that favorable conditions for inter-sectoral innovation can be achieved through niche protection, complemented by path dependency in organizational routines and culture.

\section{Sektorkopplung erneuerbarer Energien in einer experimentellen Umgebung}

Erkenntnisse aus einem Pilotprojekt für intelligente Energiegebäude in Österreich

Die Integration von bisher nicht miteinander verbundenen Sektoren des Energiesystems gilt als eine der wichtigsten Strategien zur Reduktion von $\mathrm{CO}_{2}$-Emissionen. Viele Studien zu technischen Innovationen, die sich mit dem Übergang zu einem nachhaltigen Energiesystem befassen, konzentrieren sich auf Innovationsnischen als ein förderliches Umfeld, in dem neue Lösungen getestet und zur Marktreife gebracht werden können. Im vorliegenden Beitrag wird untersucht, wie der Schutz in einer solchen Nische in Kombination mit bestehenden Pfadabhängigkeiten die Integration erneuerbarer Energien bei Wohngebäuden be-

This is an article distributed under the terms of the Creative Commons Attribution License CCBY 4.0 (https://creativecommons.org/licenses/by/4.0/)

https://doi.org/10.14512/tatup.29.2.38

Submitted: 14. 02.2020. Peer reviewed. Accepted: 15. 05.2020 günstigt. Die Ergebnisse basieren auf einer Fallstudie zur Integration der Sektoren Strom, Wärme und Gas in einem Pilotprojekt, bei dem der lokale Energiebedarf gedeckt und flexibel Strom in das Netz einspeist wird. Unsere Ergebnisse deuten darauf hin, dass förderliche Bedingungen für intersektorale Innovation durch Schutz in der Nische, ergänzt durch Pfadabhängigkeit in Organisationsroutinen und Organisationskultur, gewährleistet werden können.

Keywords: sectoral integration, energy transitions, smart grids, pilot and demonstration projects (PDPS), green buildings

\section{Introduction}

A stronger integration of different sectors of the energy system is seen as one of the key strategies to support the transformation towards greater sustainability. The underlying rationale behind the concept is to move away from sector-specific approaches that only consider solutions within sectors, and instead adopt a more holistic approach to all sectors, allowing for energy-efficient and more cost-effective overall configurations. There are numerous options in which technical applications from different sectors can be combined to achieve significantly higher efficiency levels (BDEW 2017). The term smart energy system is used in the literature when referring to energy concepts in which various forms of energy and sectors are combined with computing-based control technology to create increasingly efficient solutions (Lund et al. 2017).

However, several regulatory, organisational, economic, and technical problems limit the widespread implementation of such solutions. In addition, approaches to the integration of different sectors often lead to greater complexity and thus to new and difficult-to-estimate risks in practice (Büscher 2018). 
In this paper, we present a case study from Austria in which the heat, gas and electricity sectors were coupled. The underlying empirical investigation was carried out in 2016 and 2017 as part of the European project MATCH ${ }^{1}$. During two site visits, a total of seven qualitative interviews were conducted: with the project manager as well as two people involved in the project, and with three residents of the housing estate. The interviews were transcribed and analysed using content analysis software. In addition, written material (reports, project descriptions) was included in the case study. for the entire energy system as well as for underlying individual sub-systems.

However, in practice sectoral coupling combined with renewable energy sources faces several unresolved problems. Wietschel et al. (2018) discuss a number of issues for the German context that need to be addressed if integrated solutions are to become more widespread in the energy system. These include macro and sectoral level issues such as regulatory and legal aspects, economic considerations of costs and revenue opportunities, IT issues, supply-side and consumption-side potentials,

\section{The coupling of different sectors of the energy system usually leads to greater complexity and thus brings about new and difficult-to-estimate risks.}

In the text below we demonstrate and discuss the results of this study. We examine why the technologically advanced pilot project could be realised and how the project was perceived by the end users. Before discussing the case study in more detail, the following section presents the theoretical approaches through which the findings are viewed and analysed.

\section{Innovation, strategic niches, and path dependencies in sector coupling of renewable energy}

A definition of innovation in sector coupling of renewables, which can be considered to align most closely with the goals of energy transition strategies in the EU, most notably in Germany, is the one provided by the German Association of Energy and Water Industries (BDEW): "the energy engineering and energy economy of the connection of electricity, heat, mobility and industrial processes, as well as their infrastructures, with the aim of decarbonisation, while simultaneously increasing the flexibility of energy use in the sectors of industry and commercial/trade, households and transport under the premises of profitability, sustainability and security of supply" (BDEW 2017). Intersectoral coupling intends to achieve several synergies in energy production and consumption. According to Lund et al. (2017), these include, amongst others, much better use of waste heat, more flexible CHP production, or better balancing of the electricity grids and thus greater integration of renewable energies. The coupling of sectors that have, up until now, mostly existed independently is expected to bring advantages

1 The project MATCH (Markets, Actors and Technologies - A comparative study of smart grid solutions) was funded by the ERA-Net Smart Energy Systems programme and involved partners from Austria, Denmark, and Norway, and ran from February 2016 to October 2018. Project website: https://www.match-project.eu/. and practical challenges for the implementation as well as social science aspects such as micro-level acceptance of specific integrated solutions.

History has shown that the coupling of different sectors of the energy system usually leads to greater complexity and thus brings about new and difficult-to-estimate risks. Büscher and Sumpf (2015) argue that smart technology and new business models will create socio-technical problems as they rely on structural coupling of technology and communication. This makes it difficult to predict and control these systems, jeopardises the reliability of output, and causes a lack of transparency. Moreover, the solutions to these problems change over time and differ across contexts so that all solutions are indeed temporary and simultaneously create new problems (Büscher 2018). However, under the current regulatory framework operators of smart energy systems are also exposed to certain risks, for example with regard to their actual ability to make a profit (Leisen et al. 2019). This situation could also be found in the present case where the coupling of several energy sectors was realised in a strategic niche context.

One of the most prominent frameworks used to understand the socio-technical factors and processes required for system-wide sustainable energy transitions that are reinforced by developments at the local, project and individual levels, is strategic niche management (SNM) (Schot and Geels 2008). The SNM approach suggests that innovation processes that can potentially lead to regime-wide transformations can be enabled through experimentation and mutual alignment of technology design, user practices, and regulatory structures in technological niches (Schot 1992; Rip and Kemp 1998). Niches are spaces protected from market competition (similar to the infant industry argument in international trade) where firms and industries develop variations which do not yet fit the existing selection environment. The probability of being competitive (over time) is increased because initial trial-and-error processes are confined 
to a scale where the cost of errors is both relatively predictable and accounted for.

The premise of transformation in technological niches is partially determined by diversity in the sense that different actors are present, and also that they differ from who was previously part of the group (Sengers et al. 2019). For example, the seminal approach to the technological regime states that stability and continuation can be achieved through collectively shared cognitive routines (Nelson and Winter 1982; Dosi 1982) which are aligned with those of engineers and investors in the dominant trajectory. The niche approach emphasises the importance of alignment of different actors, structures and processes such as scientists, policymakers, industry, infrastructures, and cultural significance (Kemp 1994).

The majority of empirical cases on which niche concepts have been tested are engineering research and development (R \& D) contexts such as experiments or pilot and demonstration projects (PDPs) (Hoogma et al. 2002) which are part of a national innovation strategy. PDPs are required for learning about a new technology at corporate level (Rosenberg and Steinmueller 2013), and indeed most studies conclude that this is the main outcome of this type of setting (Brown and Vergragt 2008; Frishammar et al. 2015), with the guiding vision being competitiveness, job creation, and growth at national level. Learning from PDPs can be categorised into different types, such as, for example, technical learning effects, organisational learning effects, policy learning effects, and market learning effects as categorised by Bossink (2017) who found technical learning to be the most important reason for organisations to invest in PDPs in sustainable energy.

More recently however, PDPs have taken on different roles in the innovation system and are also being framed as policies for sustainability transitions (Geels and Schot 2007). This shift can be likened to strategically placed vehicles to achieve not only traditional policy goals of employment and growth, but also assist with integrating broader societal and environmental values into technology development (Huguenin and Jeannerat 2017).

National innovation system strategies targeting innovation in complex technologies such as renewables integration in energy systems rely upon systems integration capabilities which are highly path-dependent (Rycroft and Kash 2002). These technological capabilities integrate diverse scientific and engineering knowledge bases that are required for complex product, process and systems innovation. Integrating and combining different technologies at micro level depends heavily upon their availability at the local level (Hansen 1992; Maskell and Malmberg 1999).

Capabilities and routines at corporate level directly influence how a company carries out its production processes, but most importantly how innovative it is. According to Coombs and Hull (1998), three aspects of the company can be used to define its path dependence: (1) its "technology as hardware" which includes physical artefacts such as, for example, products, machinery, equipment, and software; (2) the company's "knowledge base", and (3) the company's "organisational routines" on which it depends to conduct its regular business (Coombs and Hull 1998, p 243). Knowledge bases can be defined in various ways, but Hodgson (1993), cited in Combs and Hull (1998), emphasises "corporate culture" and "competencies" to "mould the individual perceptions, preferences, abilities and actions of its personnel". Trust and loyalty are the outcomes of this capacity as well as cultural institutional aspects such as practices and habitual ways of thinking. Regarding the third aspect, corporate path dependency depends upon what the company does in practice, for example specific "knowledge management practices" (Coombs and Hull 1998, p. 244). Such practices can, for example, be formal or informal, paper-based or electronic, people- or system-driven, focused on knowledge management or peripheral to it.

The following case study applies these perspectives when examining favourable conditions for the coupling of different energy sectors in a highly ambitious pilot project in Salzburg, Austria.

\section{Renewables integration in a smart energy system pilot project in Austria}

The case study analyses a local smart energy system (Lund et al. 2017) that was realised as a pilot project in a new residential building complex. The project combines smart electricity, thermal and gas grids with thermal storage to harness synergies between the different sectors. The aim of the configuration is to use the housing complex as an active element in the electricity grid and thus make the grid more flexible without compromising the needs of the residents. The applied smart energy system works according to the following basic "logic": the building consumes electricity when the price is low (which is when the share of renewable energies in the grid is large) and it produces electricity when the feed-in tariff is high. The required flexibility is mainly provided by on-site heat storage.

The pilot project, later called Rosa Zukunft ${ }^{2}$, started as a nationally funded research project under the umbrella of the smart grids model region Salzburg in 2011. It was conducted by a consortium including the local energy supplier (Salzburg AG), a non-profit housing developer (Salzburg Wohnbau), and a main technology provider (Siemens Austria) together with several research institutes (Austrian Institute of Technology, CURE, Fichtner, and the Vienna Technical University). This team developed the technical concept and related planning requirements for the project. Together with additional housing developers and a company for social services as well as an engineering office, eight residential buildings with 129 apartments were planned and constructed almost simultaneously to launch-

2 The term Rosa Zukunft combines a reference to the location of the residential building complex (Rosa-Hoffmann-Straße [street name] in Salzburg) with the seminal orientation of the technical concept. 
ing the research project. Construction was started in 2012 and the first residents moved in in late 2013. The city of Salzburg supported the project by providing attractive framework conditions such as housing subsidies for the installation of photovoltaic (PV) systems.

As a pilot project, Rosa Zukunft had wide-ranging technical and social ambitions. In addition to the smart energy system solution which is at the centre of this paper, a one-year demand-response trial was conducted with selected households (Salzburg AG 2015). Furthermore, it was planned to provide electric vehicles to some residents and to have these integrated into the energy concept as controllable load. However, this part of the project could not be realised because of a lack of demand.

The smart energy system that was implemented consists of a number of different elements: technologies to produce and consume electricity on-site, technologies to store and distribute energy in the form of heat, smart control technologies to run the system as automatically as possible, and connections to electricity, gas and district heating infrastructures. The entire smart energy system is owned and operated by the energy supplier (Salzburg AG), and most of the essential technical equipment is located in one of the eight residential buildings of the complex ("technical room").

Broadly speaking, in practice this system works as follows: the energy supplier creates a simulated price curve which is updated daily. It is made up of assumed grid and electricity costs (based on the actual stock exchange price). The information is transmitted daily to the control unit of the local system and used to control the plant the following day. Based on this and additional information about the expected energy needs of the build- both economically advantageous and useful to the grid, e.g. to support the integration of flexible renewable generation facilities throughout the grid.

The 129 apartments in the complex and the communal facilities are supplied with thermal energy for hot water and heating needs through a micro grid. To guarantee the energy supply to consumers, the pilot project's micro grid is additionally connected to the district heating network (backup). The PV panels installed on the roofs of the residential complex are also operated by the project owner but are not integrated into the smart energy system. The electricity produced is simply fed into the grid.

According to the interviewees involved in the project, the system has proven to be effective in practice. The main objectives of the project were achieved: the heat supply to households is working with great reliability except for a few problems during the start-up phase. Only economic efficiency is suboptimal because of backup facilities and oversized technical elements. Compared with a conventional energy system, however, this case exhibits a number of specific issues.

It is evident that such a project involves higher levels of technical, legal, financial, and organisational complexity. The planning and building of the applied system were highly dependent on extensive use of computers and electrical engineering, mainly because of the nature of the equipment and the sophisticated modelling and programming that is involved in making such a system work well. It took considerable effort to calculate not only the building complex's specific energy needs and at what times energy was required, but also to design the corresponding size of the energy production and storage units. During the construction phase, the project needed significantly more effort

\section{Synergies across the sectors of smart electricity, thermal and gas grids together with thermal storage can make the housing complex an active element in the electricity grid.}

ing, the system can work in two modes: either in the "electricity production mode" or in the "electricity consumption mode". In the former, electricity is generated on-site using a CHP plant that runs on biogas. The electricity is supplied to the public grid, and the waste heat from the plant is used to heat water in a large storage tank $\left(90 \mathrm{~m}^{3}, 18 \mathrm{~m}\right.$ tall) which is integrated into one of the buildings. In the other mode, when electricity is to be consumed because of favourable stock exchange prices, a heat pump is activated. It uses groundwater from six drill holes located 200 below the ground to produce heat energy which is also stored in the large on-site tank. In both operating modes, the electricity and heat sectors are coupled. In the case of electricity production, the gas sector is also added. The primary goal of the configuration is to make heat production in the housing complex in coordinating and convincing the numerous partners from different areas and disciplines than traditional projects of this size. Conventional construction projects are usually developed with strong pressures regarding time and cost. Additional requirements, such as those imposed by a research project, tend to exacerbate this situation. The smart energy system also requires new technologies (e.g. the central control unit, an in-house development of Siemens AG) and new combinations of existing technologies from which risks and unforeseeable situations must be expected (Luhmann 1991). Although the project was financially supported by the public sector, the project owner also took financial risks. Extraordinary investment costs are offset by possible profits from the sale of heat and electricity. And of course, there was uncertainty in the beginning as to how users would re- 
act. In our interviews, for example, some residents complained about what they perceived to be the energy supplier's monopoly position. In fact, the monopoly situation exists only regarding the heat supply. However, because of joint invoicing (Salzburg AG provides heat, electricity, water, and telecommunication services), some residents got the impression that they could only purchase electricity from the project owner, which was not the case.

Building on the results and experience gained from the pilot project, the project owner has now implemented several similar projects. However, these projects have a simpler design, the storage tanks are significantly smaller, there are no heat pumps, and the systems are not controlled by a simulated price curve (which is also no longer used in the pilot project). Although these follow-up projects combine different forms of energy, they are not designed to balance the electricity grid because there is currently no functioning market for this in Austria. The aim of these projects is to achieve optimal economic performance under current market conditions.

\section{Discussion}

The smart energy system implemented in the course of the pilot project involved the coupling of different sectors in order to create an efficient and renewable solution. However, the implemented solution is limited in both size and impact. According to the project management, the objective was to build a functioning pilot plant and thus gain hands-on experience. The case study shows that even small, locally bounded smart energy systems are
Salzburg AG, which has been working on technical smart grid research projects since 2004, was awarded the national programme contract for the Smart Grids Model Region Salzburg together with two partners (Siemens AG and Salzburg Wohnbau) as part of the New Energies 2020 national funding framework. New Energies 2020 was one of several programmes of the Climate and Energy Fund which was created two years earlier to support the federal government in implementing the Austrian Climate Strategy (Klima- und Energiefonds 2010). Within the framework of the designated model region, knowledge from previous projects was consolidated, providing the basis for the planning and implementation of several other pilot and demonstration projects. The overall objective of the model region was to conduct comprehensive research into the various options that smart grid technology potentially offers for the transition of the energy system (bmvit 2010).

The status as a model region helped to provide access to research funding and reinforced the normative orientation of the projects aimed at developing technologies for a decarbonised energy economy (Klima- und Energiefonds 2010). However, this strong research orientation resulted in designing a project for potential future framework conditions (e.g. clear price signals from the electricity market) and favoured a solution based on technical feasibility rather than on economic considerations (e.g. heat pump and CHP, oversized storage tank, district heating connection). A further consequence of the activities conducted over several years within the model region was the establishment of a strong network of actors consisting of energy companies, technology providers, research institutions, housing developers, and contractors. The pilot project Rosa Zukunft could be accom-

\section{Even small, locally bounded smart energy systems are associated with high demands on planning and implementation as well as with new risks.}

associated with high demands on planning and implementation as well as with new risks. Subsequently, we will discuss two specific circumstances found at the project level in this example of sector coupling, which were important for the implementation.

The first condition results from the fact that this was a publicly funded pilot project (Salzburg AG 2015). Pilot projects usually take place in a "protected space" (Smith and Raven 2012) that supports broad experimentation with new solutions. This is essential because technologies in early phases of development require strategic support to protect them against market forces and allow for the improvement of performance, price, and infrastructures because of their immaturity (Raven et al. 2016). This was true for this pilot project as Rosa Zukunft was one of three major pilot projects part of a nationally funded smart grid initiative (Salzburg AG 2015). plished not least because most of the participating partners had already been involved in earlier projects, allowing them to jointly acquire knowledge and build mutual trust (Salzburg AG 2015).

The status as a model region and the associated research funds were undoubtedly of central importance for the pilot project. However, the protected space was also created as a result of additional factors. The research activities of various Salzburg AG departments were strongly promoted and supported by the management, the national energy regulator approved the use of the simulated price curve to control the plant, and the city and region of Salzburg provided helpful political support.

In addition, the project benefited from existing internal company path dependencies. This aspect is closely related to the history and corporate culture of the project owner and leading player of the model region activities, the Salzburg AG. Not only 
is Salzburg AG the main regional energy provider, it is also a multi-utility firm covering the fields of electricity supply, natural gas, district heating, water, telecommunications, and transport. Today's Salzburg AG was formed in the year 2000 from merging two different companies, the municipal utilities of Salzburg and the former provincial energy supplier (SAFE). Both predecessors have existed for more than one hundred years. To this day, Salzburg AG is majority-owned by the city and province of Salzburg (Eymannsberger and Kurtz 2017). With this particular history, Salzburg AG was well suited to deal with smart grids in the early 2000s. The associated vision of linking various sectors and business areas has long been part of the firm's identity and culture.

As a result of market liberalisation in the energy sector, the network operator Salzburg Netz GmbH was founded in 2006. This company operates the distribution networks for electricity and gas in the province of Salzburg and is a $100 \%$ subsidiary of Salzburg AG (Eymannsberger and Kurtz 2017). In our case study we could observe that the separation of energy provider and network operator was thus only implemented on paper. The two companies share common headquarters and there were almost no institutional barriers for the cooperation of the two companies within the smart grids model region. This form of "easy unbundling" also helped with the implementation of the pilot project. An existing common organisational structure, familiar internal company processes, a common identity, and the physical proximity of the necessary specialist departments contributed to the management of amplified requirements during the set-up of the local smart energy system.

\section{Conclusion}

This pilot project is one of those examples where the coupling of different sectors in order to increase the efficiency and use of renewable energies has been implemented to a very high degree, especially when compared internationally. However, the project is local and limited in size and impact. Despite these limitations, the implementation of the project was associated with a number of uncertainties and risks as well as additional difficulties. The project required higher levels of technical, organisational, legal, and financial complexity. Extensive simulations and model calculations were necessary during the planning stage, considerably more actors were involved in the implementation than in a conventional project, legal exceptions were necessary for the use of the simulated price curve, and because of a lack of experience and the non-existent market for demand response services, there were also financial risks for the project operator.

We have shown how the pilot project works in practice, which sectors are connected in what ways and with which objectives. We outlined the history of the project and found that both a protected space in a specially created innovation niche and long-standing path dependencies contributed to the characteristics of the chosen approach of the pilot project and its success- ful implementation. This also allowed potential technical, economic, and organisational risks to be managed effectively. However, on the end user side, criticism was expressed about the resulting monopolistic situation associated with this solution. The fact that the experience gained in the pilot project was only partially implemented in subsequent activities of the project operator is mainly the result of a lack of a favourable economic and legal framework for such projects.

\section{References}

BDEW - Bundesverband der Energie- und Wasserwirtschaft e. V. (2017): Positionspapier. 10 Thesen zur Sektorkopplung. Available online at https://www.bdew. de/service/stellungnahmen/10-thesen-sektorkopplung/, last accessed on 27.01.2020

bmvit - Austrian Federal Ministry of Transport, Innovation and Technology (ed.) (2010): Smart grids showcase region: Salzburg. Integrated infrastructure in Salzburg. Vienna: Austrian Federal Ministry of Transport, Innovation and Technology.

Bossink, Bart (2017): Demonstrating sustainable energy. A review based model of sustainable energy demonstration projects. In: Renewable and Sustainable Energy Reviews 77, pp. 1349-1362. D0I: 10.1016/j.rser.2017.02.002.

Brown, Halina; Vergragt, Philip (2008): Bounded socio-technical experiments as agents of systemic change. The case of a zero-energy residential building. In: Technological Forecasting and Social Change 75 (1), pp. 107-130.

Büscher, Christian; Sumpf, Patrick (2015): "Trust" and "confidence" as socio-technical problems in the transformation of energy systems. In: Energy, Sustainability and Society 5 (1), p. 13. DOI: 10.1186/s13705-015-0063-7.

Büscher, Christian (2018): Framing energy as a sociotechnical problem of control, change, and action. In: Christian Büscher, Jens Schippl and Patrick Sumpf (eds.): Energy as a sociotechnical problem. An interdisciplinary perspective on control, change and action in energy transitions. London: Routledge, pp. 14-38.

Coombs, Rod; Hull, Richard (1998): 'Knowledge management practices' and path-dependency in innovation. In: Research Policy 27 (3), pp. 237-253.

Dosi, Giovanni (1982): Technological paradigms and technological trajectories. A suggested interpretation of the determinants and directions of technological change. In: Research Policy 11 (3), pp. 147-62.

Eymannsberger, Helmut; Kurtz, Klemens (2017): Salzburg AG. Regionalwirtschaftliche Bedeutung und Wertschöpfungsanalyse. Available online at https://www.salzburg-ag.at/content/dam/web18/dokumente/presse/ Wertschoepfungsstudie_Salzburg\%20AG.pdf, last accessed on 12.05.2020.

Frishammar, Johan; Söderholm, Patrik; Bäckström, Kristoffer; Hellsmark, Hans; Ylinenpää, Håkan (2015): The role of pilot and demonstration plants in technological development: synthesis and directions for future research. In: Technology Analysis \& Strategic Management 27 (1), pp. 1-18.

Schot, Johan; Geels, Frank (2007): Niches in evolutionary theories of technical change. In: Journal of Evolutionary Economics 17 (5), pp.605-622. DOI: 10.1007/s00191-007-0057-5.

Hansen, Niles (1992): Competition, trust, and reciprocity in the development of innovative regional milieu. In: Papers in Regional Science 71 (2), pp. 101-102.

Hodgson, Geoffrey (1993): Corporate culture and the nature of the firm. In: Judge Institute of Management Studies Working Paper No. 14, 1993-94. Cambridge: University of Cambridge. 
Hoogma, Remco; Kemp, René; Schot, Johan; Truffer, Bernard (2002): Experimenting for sustainable transport. The approach of strategic niche management. London: Spon Press.

Huguenin, Ariane; Jeannerat, Hugues (2017): Creating change through pilot and demonstration projects. Towards a valuation policy approach. In: Research Policy 46 (3), pp. 624-635.

Kemp, Rene (1994): Technology and the transition to environmental sustainability, In: Futures 26 (10), pp. 1023-1046.

Klima- und Energiefonds (2010): Geschäftsbericht 2009. Available online at https://www.klimafonds.gv.at/wp-content/uploads/sites/6/ Geschaeftsbericht2009.pdf, last accessed on 12.05.2020.

Leisen, Robin; Steffen, Bjarne; Weber, Christoph (2019): Regulatory risk and the resilience of new sustainable business models in the energy sector. In: Journal of Cleaner Production 219, pp. 865-878.

Luhmann, Niklas (1991): Soziologie des Risikos. Berlin: de Gruyter.

Lund, Henri; Østergaard, Poul Alberg; Connolly, David; Mathiesen, Brian Vad (2017): Smart energy and smart energy systems. In: Energy 137, pp. 556-565.

Maskell, Peter; Malmberg, Anders (1999): Localized learning and industrial competitiveness. In: Cambridge Journal of Economics 23 (2), pp. 167-185. DOI: 10.1093/cje/23.2.167.

Nelson, Richard; Winter, Sidney (1982): An evolutionary theory of economic change. Cambridge: Harvard University Press.

Raven, Rob; Kern, Florian; Verhees, Bram; Smith, Adrian (2016): Niche construction and empowerment through socio-political work. A meta-analysis of six low-carbon technology areas. In: Environmental Innovation and Societal Transitions 18, pp. 164-180.

Schot, Johan (1992): Constructive technology assessment and technology and technology dynamics. The case of clean technologies. In: Science, Technology, \& Human Values 17 (1), pp. 36-56.

Rip, Arie; Kemp, René (1998): Technological change. In: Steve Rayner and Elizabeth Malone (eds.): Human choice and climate change. Vol. 2. Columbus: Battelle Press, pp. 327-399.

Rosenberg, Nathan; Steinmueller, W. Edward (2013): Engineering knowledge. In: Industrial and Corporate Change 22 (5), pp. 1129-1158.

Rycroft, Robert; Kash, Don (2002): Path dependence in the innovation of complex technologies. In: Technology Analysis \& Strategic Management 14 (1), pp. 21-35.

Salzburg AG (ed.) (2015): Resultate \& Erkenntnisse aus der Smart Grids Region Salzburg. Zusammenfassung. Available online at http://www.smartgrids salzburg.at/content/dam/websites/smartgrids/Downloads/SG_ Erkenntnisbericht.pdf, last accessed on 12.05.2020.

Schot, Johan; Geels, Frank (2008): Strategic niche management and sustainable innovation journeys. Theory, findings, research agenda, and policy. In: Technology Analysis \& Strategic Management 20 (5), pp. 537-554.

Sengers, Frans; Wieczorek, Anna; Raven, Rob (2019): Experimenting for sustainability transitions. A systematic literature review. In: Technological Forecasting and Social Change 145, pp. 153-164.

Smith, Adrian; Raven, Rob (2012): What is protective space? Reconsidering niches in transitions to sustainability. In: Research Policy 41, pp. 1025-1036.

Wietschel, Martin et al. (2018): Sektorkopplung. Definition, Chancen und Herausforderungen. Diskussionspapier im Rahmen des Kopernikus-Projekt „Systemintegration“. Karlsruhe: Fraunhofer ISI.

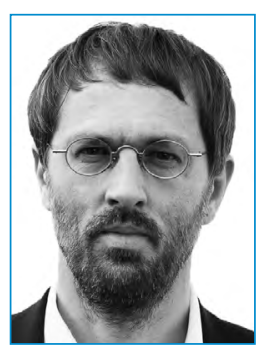

PRIV.-DOZ.MAG.DR . MICHAEL ORNETZEDER

is a Senior Researcher at the Institute of Technology Assessment (ITA), Austrian Academy of Sciences. He has PhD and post-doc level research and teaching experience in technology assessment and science and technology studies, with a particular focus on energy transitions, sustainable energy technologies, user innovation, and social learning.

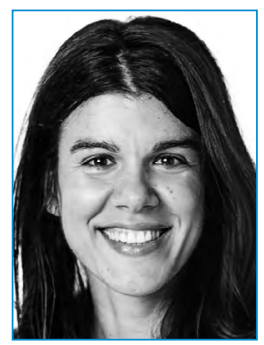

\section{DR. TANJA SINOZIC}

is a Senior Researcher at the Institute of Technology Assessment (ITA), Austrian Academy of Sciences. Since joining the ITA in 2015, she has been working on energy transitions in Austrian regions. She was originally trained in economics and regional planning before obtaining a PhD in Science Policy at the Science Policy Research Unit (SPRU), University of Sussex. 


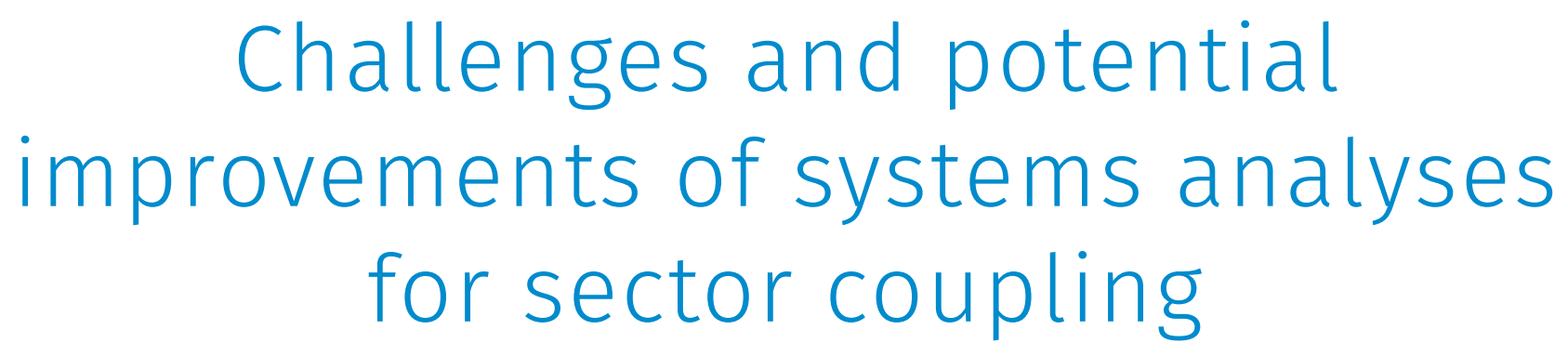

A discussion along the dimensions of socio-technical problems

Bert Droste-Franke, IQIB - Institut für qualifizierende Innovationsforschung \& -beratung, Wilhelmstr. 56,

53474 Bad Neuenahr-Ahrweiler (bert.droste-franke@iqib.de)

This paper discusses the challenges of systems analysis for policy advice in the context of sector coupling along the three dimensions of socio-technical problems: control, change, and action. Research shows that the challenges of systems analyses increase significantly when considering sector coupling, both with respect to the choice of areas of investigation and with respect to the basic methods and practices of systems analysis for policy advice. In particular, social aspects and practical expertise need to be considered, results of different studies should ideally be combinable for reflexive meta-analyses, and analyses should focus on key messages.

\section{Herausforderungen und Möglichkeiten zur Verbesserung von Systemanalysen zur Sektorkopplung}

Eine Diskussion entlang der Dimensionen soziotechnischer Probleme

In diesem Beitrag werden Herausforderungen der Systemanalyse für die Politikberatung im Bereich der Sektorkopplung entlang der drei Dimensionen soziotechnischer Probleme diskutiert: Kontrolle, Veränderungsprozesse und Handlungen. Es zeigt sich, dass Herausforderungen von Systemanalysen unter Berücksichtigung der Sektorkopplung deutlich steigen, sowohl hinsichtlich der Wahl der Untersuchungsbereiche als auch hinsichtlich der grundlegenden Methoden und Praktiken der Systemanalyse zur Politikberatung. Insbesondere gesellschaftliche Aspekte und praktische Expertise müssen berücksichtigt werden, Ergebnisse verschiedener Studien sollten idealerweise für reflexive Metaanalysen kombinierbar sein und die Analysen sollten sich auf die wichtigsten Aussagen konzentrieren.

Keywords: systems analysis, challenges, sector coupling, robustness, energy supply

This is an article distributed under the terms of the Creative Commons Attribution License CCBY 4.0 (https://creativecommons.org/licenses/by/4.0/)

https://doi.org/10.14512/tatup.29.2.45

Submitted: 17. 02.2020. Peer reviewed. Accepted: 15. 05.2020

\section{Introduction}

Current plans for modifying energy systems in order to meet greenhouse gas reduction targets particularly include using much more fluctuating renewable energy sources than nowadays. Thus, the need for system flexibility increases significantly (Ausfelder et al. 2017). Ensuring secure and safe energy supply in spite of such a system transformation process requires to intelligently combine electricity and heat supply as well as applications in sectors with large energy consumption. This means to come much closer in touch with societal habits and needs than in current energy systems. As result "socio-technical problems" may arise from energy transition processes. Büscher (2018) made up three facets which are to be analyzed in this context: the problems of control, change and action. In this contribution these dimensions are taken for structuring the discussion of challenges connected with energy system analyses as identified by Droste-Franke et al. (2015), sketching additionally first experiences from practical attempts to improve systems analyses with the focus on sector coupling.

\section{General challenges of systems analyses}

Droste-Franke et al. (2015) analyses challenges of systems analyses for policy advice following the approach of rational technology assessment, using ethical reflection to propose rational options (Decker and Grunwald 2001; Grunwald 1999; Grunwald and Saupe 1999; Decker 2004). Accordingly, a scientific expert group was set up, extended by further experts in two workshops. Recommendations for the design of systems analysis were elaborated in intensive interdisciplinary reflections on framework conditions and on the virtue of systems analyses for policy advice. Lines of rational arguments were made visible and as far as possible preconditions and causal links as well as 
descriptive and normative elements were dissected to derive recommendations.

Droste-Franke et al. (2015) focus on general challenges of systems analyses for policy advice. Basic results from their argumentation taken up here are

- the need for dynamic stability and social robustness in solutions and analyses,

- recommendations on how to proceed in typical systems analyses to reach such a robustness, and

- a specific culturally based systems view supporting to distinguish systems and their environment as well as to evaluate the explanatory power of analyses.

In their argumentation Droste-Franke et al. (2015) start with general aims of an energy supply system. Following them, basic requirements are that

- the system should be designed in a way that the essential function of providing usable energy to the consumer can be guaranteed and

- unintended "negative side effects should not outweigh the intended effects" (ibid, p.5).

Having in mind the increasing amount of fluctuating and non-disposable power in the system, besides safety also security requires particular attention when designing future energy systems.

The proposed concept of dynamic stability is basically referring to two requirements for future energy supply: robustness and opportuneness (Ben-Haim 2006; Carrier 2010). Robustness means that solutions for energy supply ensure "staying within an admissible corridor where one is safe against adverse effects" (Droste-Franke et al. 2015, p.9). Opportuneness means unforeseen circumstances. For this purpose, it is important to analyses a full range of options. The focus should be laid on their striking features which mean difference for decisions on human action. Furthermore, the technologies employed "should operate in conformity with the interests and values professed within the society concerned" (ibid, p. 39). A typical process could be designed in a way that in a first step an analysis of options is carried out from which in a second step, preferred options can be selected by taking the interests and valuations of the concerned society into account. This should ideally be done by comprising a wide range of interests. Final decisions on actions to take have to be made by legitimated political bodies.

The systems view taken by Droste-Franke et al. (2015), based on Janich (2001), was specifically designed to support the design of new studies and the evaluation of existing studies. Its fundamental approach is to distinguish systems from their environment in two orthogonal dimensions: the operational and the intentional dimension ("systems-web approach") (DrosteFranke et al. 2015; Droste-Franke 2015). Following this system perception, in the operational dimension a system develops automatically from the formal operation which corresponds to the disciplinary perspective taken to describe certain circumstances: characteristics of entities which can be influenced by the operation are part of the system, all other characteristics of entities belong to the environment (operationally closed system). In the intentional dimension, the intention of the analysis carried out allows to clearly separate the elements of the system from its environment: all characteristics of entities which are seen as relevant for the purpose of analysis are elements of the system, all others are not (intentionally closed system). Combining both dimensions results in the view that a system consists of all characteristics of entities which are affected by the chosen formal operation which are relevant for the purpose of analysis. For instance, the "energy supply system" unfolds as a bundle of character-

\section{Expert advice should be a reliable guide to secure energy supply even under unforeseen circumstances.}

to ensure that "we are able to take advantage of opportunities that open up unexpectedly" (ibid, p. 9). The market is not able to stimulate such solutions by itself. Instead a "comprehensive scheme, which is best developed by drawing on foresight and epistemic penetration, is required ... This is why science-based policy advice can prove helpful in exploring the dynamically stable pathway toward a robust energy supply system." (ibid, p. 12). Social robustness means "that at an expert analysis or recommendation is acceptable within a wide spectrum of diverse interests and value commitments" (ibid, p. 13). It aims to achieve social inclusion in order to elaborate acceptable solutions.

According to the types of solutions needed, expert advice should be a reliable guide to secure energy supply even under istics of elements which, according to their chosen formal descriptions, have influence on conditions of supply and consumption of usable energy. For instance, from the physical perspective, energy fluxes to entities which cannot be used for energy supply represent energy losses from the system and are thus released to the system's environment. Relevant operations include all scientific and practically based descriptions or disciplinary perspectives (social, technical, economical, psychological etc.) which are relevant for the design of future energy supply systems.

In the following, more detailed insights to challenges of systems analyses for policy advice and potential solutions are discussed along the approach of socio-technical problems. 


\section{Challenges of systems analyses along three dimensions of socio-technical problems}

\section{Three dimensions of socio-technical problems}

Büscher (2018) defines three "dimensions" or "facets" of sociotechnical problems, control, change, and action, which are used to get a deeper insight into problems arising with the energy transition. These are taken here as starting point for structuring the more detailed discussion of particular challenges for systems analyses in the context of sector coupling. Büscher (2018) makes up three facets, as briefly sketched in the following:

- The problem of control: It includes structural characteristics of systems, particularly, the aspect of knowing about "relations of heterogeneous elements", in order to enable operating energy supply according to societal needs. Technical issues and social issues are distinguished here as well as internal (system) and external (environment) issues.

- The problem of change: It is defined by Büscher (2018) as a trade-off between enabling change and ensuring security by redundancy. In this facet institutional aspects are particularly addressed.

- The problem of action: this facet concentrates on problems of operation and decision making which develop particularly when technical processes are substituted by social processes with different time scales and higher simultaneity. According to Büscher (2018) increasing uncertainty can be absorbed by social arrangements or technical devices providing trust and confidence.

A discussion of these three facets of socio-technical problems can also be found in the introduction (pp.11-16) and in Büscher et al. of this TATuP special topic (pp. 17-23).

\section{Considering the problem of control}

For the problem of control, various technical and social aspects need to be taken into account: the complete chain of interacting elements applied for energy supply (energy supply system), impacts of circumstances in the environment on this system, and vice versa, and options of inputs to the system needed for reaching a certain expected output. As the chain consists of technical as well as social elements, a necessary synchronization of all processes is very complex, especially if circumstances change.

Control is the domain for which particularly system knowledge is needed. In order to capture all problems of this dimension, first the knowledge about the system and all processes to establish and operate a system need to be known. As introduced above we follow here the system perception of Droste-Franke et al. (2015), distinguishing an operational and an intentional dimension. In order to analyses an energy system and its linkages to other sectors with respect to its future design, societal and natural framework conditions need to be taken into account.
Thus, in addition to formal descriptions of physical and technical aspects perspectives of social and psychological science, but also of other natural and especially geo-sciences etc. are required. Additionally, scientific insights need to be supplemented by practical aspects in the areas of regulations, responsibilities, knowledge and societal and individual beliefs etc. In this way a web of descriptions develops which becomes denser with each perspective complemented.

The necessity of considering the individual disciplinary perspectives comes with the necessity of analyzing the inter-connections via the involved entities in an interdisciplinary manner. Exchange between the systems takes place via the entities. Processes in one system may lead to changes in entity characteristics relevant for another system.

Scientific means are designed to provide general descriptions which here need to bear in a certain fixed context of application. In order to be able to provide epistemic robustness, additionally the following practical expertise is needed:

- technical expertise: knowing how to follow a "fixed canon of rules" (ibid, p. 36),

- professional expertise: proceeding "on the basis of exemplars or precedents" (ibid, p. 36),

- local, experience-based expertise: "advanced knowledge in virtue of ... [the experts] familiarity with the relevant domain" (ibid, p. 41).

In most cases, these expertises can also be sorted into disciplinary description systems. An inclusion of such additional expertises can be realized by establishing respective co-design processes, including all relevant experts and stakeholders into the process. Experience has been gained in various projects, e. g. in the "FONA Research for Sustainable Development" program, project "Helmholtz Alliance ENERGY-TRANS" and Kopernikus project "ENavi". One of the projects in "FONA" is the EnAHRgie". The innovation group as the core working group was assembled following the recommendations of DrosteFranke et al. (2015). It consisted of local representatives from banks, companies, handicraft, administration, civil society organizations, energy suppliers and scientists from different disciplines: engineering science, political science, legal science, technology assessment and economics. For instance, due to the discussion process with the practitioners, the scientific analysis was significantly changed by concentrating on carrying out a multi-criterial scenario development instead of modelling the technical distribution grid which was originally planned.

With sector coupling, regulations become much more complex than without, because devices formerly used only for specific purposes like cars and heating systems need to be con-

1 EnAHRgie: Nachhaltige Gestaltung der Landnutzung und Energieversorgung auf kommunaler Ebene. Umsetzung für die Modellregion Kreis Ahrweiler, Förderung: BMBF, FONA, Innovationsgruppen „Nachhaltiges Landmanagement ", FKZ: 033L110 
nected to the energy system in order to provide more flexibility. Systems analyses of the more complex technical system become much more ambitious in many respects: options competing for the same system tasks are of different nature, are situated in different locations and on different levels of the energy supply system, e. g. the provision of balancing energy by large power plants competes with flexibly charging batteries in electric cars at home. Figure 1 shows directly competing balancing technologies. All those options need to be considered for adequate systems analyses, considering also many more societal aspects and restrictions. Furthermore, researchers of different disciplinary fields like transport and energy system research who did not cooperate before, need to work hand in hand to derive meaningful analyses.

Droste-Franke et al. (2015) show already that many energy system studies differ even in the technologies considered, with the effect that the results are not comparable. Furthermore, most of the analyses concentrate on pure cost-effective solutions. Even studies dealing with sector coupling in an interdisciplinary setting

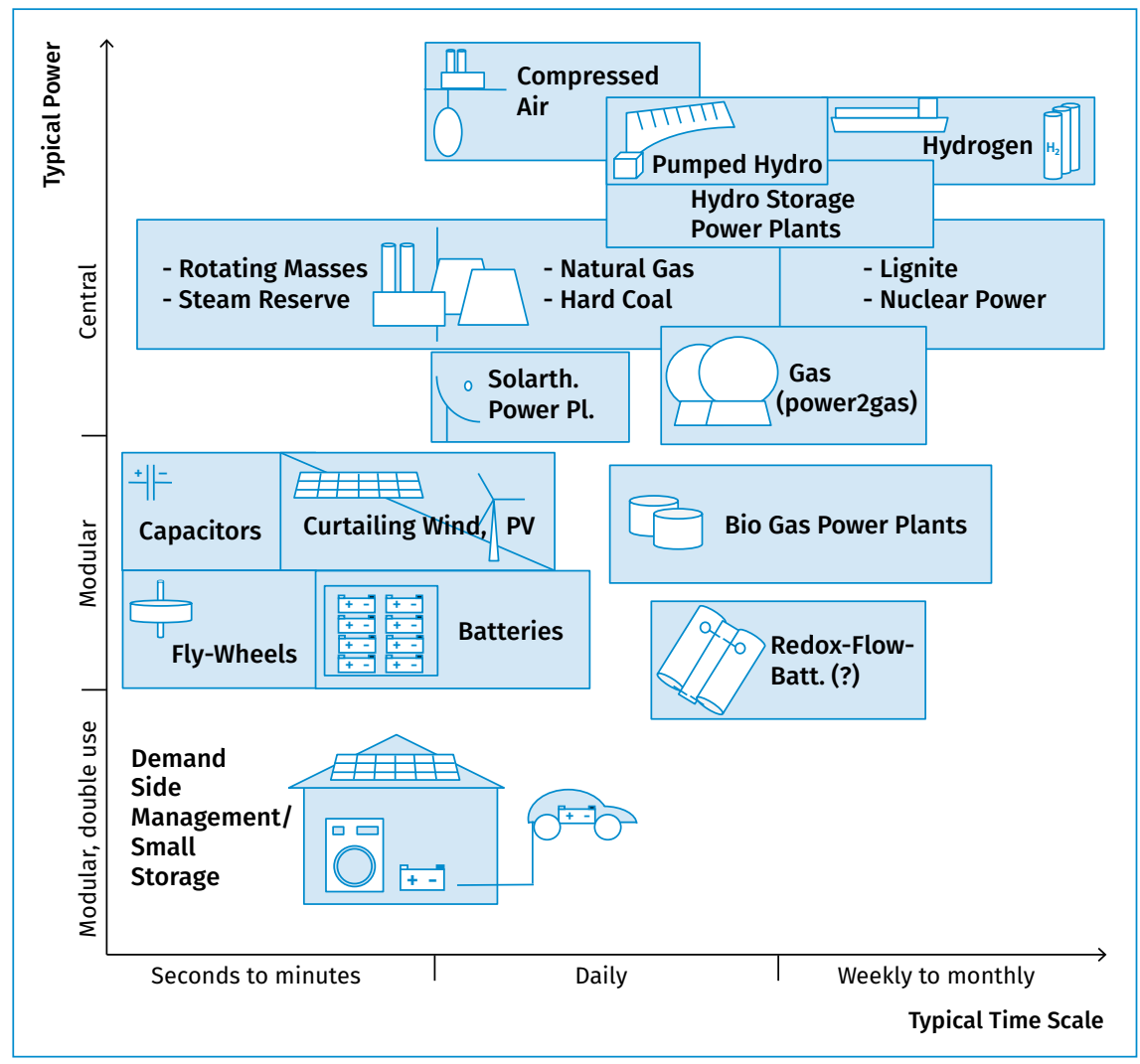

Fig. 1: Competing technologies to provide flexibility in the energy supply system (horizontally: same power range; vertically: same temporal scale).

Source: Droste-Franke et al. 2015, p. 106

like Ausfelder et al. (2017) are not able to provide a full picture. Arguing mainly from a techno-economic perspective, they miss aspects such as more concrete analysis of environmental and resource aspects, local added value, occupational effects etc. The example shows how hard it is to take all relevant perspectives in one study. Establishing studies with various foci, temporal and spatial scale which are combinable for reflexive meta-studies could be a solution here.

\section{Considering the problem of change}

As shown above, Droste-Franke et al. (2015) address the continuous problem of balancing change and security. They focus on designing an energy supply system which can provide a secure operation under a variety of framework conditions which may potentially change over time due to events external to the system. Stability of the system operation in spite of changing circumstances is emphasized as very important. Following their argumentation, the role of scientific experts for policy support is to identify a number of good solutions which can ensure stable operation under a variety of circumstances and that these can be changed as soon as superior solutions are available. This includes analyzing options for the change process which Büscher (2018) concentrates on. In designing this process, they see again the need to consider all expertise which is required in order to assure that the solution fits to the purpose.
The approach of the project EnAHRgie, already discussed for the problem of control, shows how an expert group consisting of scientific and practical experts can be compiled and consulted to develop an energy concept following the recommendations of Droste-Franke et al. (2015). By doing this, the initiated process follows a certain workflow carried out with scientific and practical experts. First, questions are collectively derived. Then appropriate systems analyses are designed and carried out. In a next step, the results are reflected and reviewed with respect to them providing answers to the posed questions. Finally, analyses are finetuned and results are updated in at least one iterative slope. The realization of the approach in the project EnAHRgie represents a variation of the workflow initially proposed by Schilperoord and Ahrweiler (2014) for the analysis of innovation networks (Droste-Franke 2018).

Carrying out meaningful systems analyses in the realm of change is a very specific endeavor, because change is particularly steeped in a large number of incremental and radical innovation processes on multiple scales, changing products, processes and structures (Ahrweiler 2010; Fagerberg et al. 2006; Schumpeter 1912). Such innovation processes take place on various levels and are by far too complex to capture them by system correlations (Kline and Rosenberg 1986). Particularly, unforeseen processes of creative destruction, as introduced by 
Schumpeter (1993), represent non-linear developments in a way that completely new elements - we could not think about beforehand - enter the scene. These can impossibly be simulated by dynamic system modelling. Nonetheless, other models like agent-based models can be applied for systems analyses in such contexts by simulating the acting of agents on a micro-level and observing what happens in the innovation system on meso-level (Gilbert 2008).

Some potentials and challenges of such analyses can be drawn from experiences with modelling innovation processes in the InnoSEn-project (the case of lithium batteries as a core technology for coupling energy and transport). ${ }^{2}$ In order to assure a model design and respective analyses which fit to the pur- vation system are continuously changing and their emergence in the future is unknown. Thus, depending on complexity and future uncertainties of relevant framework conditions, validation by comparing past situations with potential future ones is hardly possible, or not possible at all. Nonetheless, the strong descriptiveness of micro processes and the plausible patterns in results make it a well-founded tool to carry out comparative explorative analyses of measures to foster innovation dynamics. In experiments hypotheses of impacts can be tested by comparing results for different options and analyzing their emergence. As outcome, the rational foundation for the application of such measures can be further enhanced beyond merely empirically analyzing past situations. Such a tool is particularly applicable

\section{Researchers need to work hand in hand to derive meaningful analyses.}

pose, the above described workflow was initiated for the model set-up. Experts from respective national associations, innovation research, acting companies and research funding agencies were involved by three workshops. First, questions were elaborated taking into account the heuristics of technological innovation systems, then the model was built in a way to be able to answer these questions, intermediate results were discussed and the analyses were updated to achieve refined answers (DrosteFranke and Fohr 2017; Globisch et al. 2019).

The exercise of adapting the basic SKIN (Simulating Knowledge Dynamics in Innovation Networks) model developed by Gilbert et al. (2010) to model the technological innovation system exposed various challenges. From first experiences of the simulation it can be stated that micro processes can be described quite well. Simulations show reasonable results in various details of the model and modelled effects on the meso level fit well to empirical findings for such innovation processes. In addition, types of actors can be calibrated well by existing data in order to realize reasonable proportions in numbers. For modelling future processes, it has to be borne in mind that currently existing structures are subject to continuous change. Due to lack of knowledge about causal correlations in the complex realm of innovation processes, based on statistical analyses, random actors with typical characteristics are modelled instead of concrete individual actors. Furthermore, the implementation of the core evolutionary random mechanism in knowledge generation cannot be calibrated in detail, let alone validating calculations with respect to empirical data. One main reason is missing detail in data from comparable past developments including prevailing framework conditions. Furthermore, influencing framework conditions and actor structures of the technological inno-

2 Netzwerkanalyse und Simulation von Innovationsdynamiken neuer Schlüsseltechnologien im Energiebereich (InnoSEn), BMWi, FKZ: 03ET4032 to analyses measures to increase innovation dynamics for transitions processes.

Tackling the problem of change for sector coupling would mean that processes need to be developed in a way that institutions change smoothly according to technological change so that secure energy supply is ensured at each point in time. This means to ideally coordinate and consider formal and informal institutions in many places of societal action and of various temporal scopes in a way which was not needed before. An example is coordinated adequate change of curricula in education and training of the handicraft to enable and to convince installers to sell respective technical devices and to develop fitting maintenance services. This is one prerequisite for introducing harmonized combinations of devices needed for sector coupling such as (bi-directional) loading of electric vehicles, heat pumps, CHP systems, fuel cells, heat storage, (small) electrolyzers, photovoltaics, and batteries. Systems analyses combining social and technological simulations can support decision making with providing theoretical insight in socio-technical circumstances for which experience is not yet available.

\section{Considering the problem of action}

In terms of risk and uncertainty, Droste-Franke et al. (2015) discuss various kinds of hazards distinguishing two basic dimensions. The first dimension is if "all influential factors can be reasonably expected to be known" (ibid, p. 46). The second dimension is if probability estimates are available. Following the categories of risks (all influential factors and probability estimates are known), uncertainty (known outcomes, but no observable probability) and deep uncertainty or ignorance (unknown factors may exist and have strong impact), in the case of energy transition and sector coupling we have the situation of structural change in which observed probabilities may no longer hold. This holds more specifically if social processes replace technical in- 
terconnections as discussed by Büscher (2018). In such cases experience-based knowledge may be misleading as it is based upon experience under previous conditions and without the new elements in place. Systemic, theoretical knowledge-based analyses will usually have better chance to succeed in these contexts. Following Droste-Franke et al. (2015) scientific policy advice addressing uncertainty of this kind should consider three components to be able to provide valuable policy advice in complex matters:

- bringing in local knowledge and lay experience of certain important aspects which may still be important to design robust solutions;

- strengthening the knowledge base by analyzing interdependencies and causal relations further;

- providing epistemically robust advice by reducing the statements to robust results providing main messages which remain stable under all possible interpretations in the area of high uncertainty.

The challenge for systems analyses in this case is to analyses options to design processes which can be similarly reliable as technological processes despite unknown behavior of individuals. Also, in this case social simulation, e. g. via agent-based modelling, may help. Starting with a categorization of potential behavior according to different types of individuals including assumptions for its potential change in the future, e.g. for decision situations, social processes can be analyzed and measures can be designed in order to increase security of supply. This would strengthen the knowledge. In case that calibration and validation again turn out to be difficult, the analysis of striking interlinkages could at least provide better insights into potential effects. This holds particularly if stable main messages can be identified. Another challenge lies in the communication of the results. ditionally, decision makers need to be made familiar with making decisions based on such results (Droste-Franke et al. 2015).

For the definition of processes to replace technological parts of the system, e.g. implemented and tested in simulations and model experiments, incorporating practical knowledge is specifically important. Knowledge of action, technical knowledge and maybe professional knowledge, does not only comprise knowledge about the consequences of action, but also of knowledge about how to act. In order to define a scheme for action as basis for such processes in a way that it is successful and the intended impacts are accomplished (Janich 2011), even small details may be important. Particularly options to develop and transfer "tacit knowledge" - knowledge which "cannot be expressed outside the action of the person who has it" (Foray 2007) - need to be considered in respective modelling exercises and when establishing effective learning or training processes ${ }^{3}$.

Increasing flexibility of the energy system by sector coupling means establishing and coordinating many more of these processes than before, both in various sectors and on multiple levels. The need for practical knowledge for defining and establishing societal processes further emphasizes the increasing need for participatory co-design analyses as already discussed above.

\section{Conclusions}

Discussing challenges of energy systems analyses for policy support along the three facets of socio-technical problems in combination with first experiences of applying such approaches, reveals that the need for sector coupling significantly increases challenges of energy supply and systems analyses. It fosters extending systems analyses by explicitly considering societal aspects in detail and combining them to provide insight into decisive consequences of decisions. Furthermore, practical knowl-

\section{Incorporating practical and tacit knowledge is specifically important for simulations and model experiments.}

An adequate interactive visualization of the complex interlinkages implemented in the model and the main messages in the results as well as the respective uncertainties of the modelling process could establish confidence in the system on the side of the decision maker.

For the case of sector coupling, those researchers interested in providing rational orientation for decision-making have to consider many more aspects of various disciplines, on different levels of technical systems and society than before. The current difficulties with providing and communicating energy systems analyses show that new ways need to be found to provide knowledge about striking consequences of actions to decision makers, providing main messages including involved uncertainties. Ad- edge becomes more important and needs to be taken adequately into account. Additionally, analyses of various detail and on different levels should ideally be comparable or even combinable to enable reflexive meta-analyses of main correlations.

The experiences discussed show options for tackling the problems by systems analyses. They suggest that successful approaches should include more concretely:

3 Although tacit knowledge cannot be expressed, specific situations can be established in which intensive learning, e. g. via iterative imitation and correction, potentially combined with trial and error cycles, lead to a certain transfer of tacit knowledge. Modelling can consider if such situations prevail and transfer of tacit knowledge in the described way is likely in the modelled circumstances. 
- enabling close involvement or in depth and detailed consideration of expertise from science and practice in designing and carrying out meaningful systems analyses,

- modelling more of the relevant (formal) systems of various scientific disciplines and practical aspects on the basis of fundamental characteristics and behavior of entities which will prospectively remain unchanged over time,

- communicating and providing study results transparently so that they can be taken up by others for reflexive meta-analyses in concrete decision situations and maybe can even be transferred to related areas, and

- presenting results of systems analyses in a way that the public and decision makers can make themselves familiar with uncertainties and sensitivities in order to be able to assess the meaning of the results for their individual area of interest.

Thus, not only the areas of analyses need to change, but also the kind of analyses carried out and the presentation of the results. These challenges run counter to current practice and basic methodologies of systems analyses and ask for creative solutions and innovative kinds of system analyses.

\section{References}

Ahrweiler, Petra (2010): Innovation in complex social systems. An introduction.

In: Petra Ahrweiler (ed.): Innovation in complex social systems. New York:

Routledge, pp. 1-25.

Ausfelder, Florian. et al. (2017): Sektorkopplung. Untersuchungen und Überlegungen zur Entwicklung eines integrierten Energiesystems. Munich: Deutsche Akademie der Naturforscher Leopoldina e.V.

Ben-Haim, Yakov (2006): Info-gap decision theory. Decisions under severe uncertainty. Kidlington: Elsevier.

Büscher, Christian (2018): Framing energy as a sociotechnical problem of control, change, and action. In: Christian Büscher, Jens Schippl and Patrick Sumpf (eds.): Energy as a sociotechnical problem. An interdisciplinary perspective on control, change, and action in energy transitions. London: Routledge, pp. 14-38.

Carrier, Martin (2010): Scientific knowledge and scientific expertise. Epistemic and social conditions of their trustworthiness. In: Analyse und Kritik 32 (2), pp. 195-212.

Decker, Michael (2004): The role of ethics in interdisciplinary technology assessment. In: Poiesis \& Praxis, International Journal of Ethics of Science and TA 2 (2), pp. 139-156.

Decker, Michael; Grunwald, Armin (2001): Rational technology assessment as interdisciplinary research. In: Michael Decker (ed): Interdisciplinarity in technology assessment. Berlin: Springer, pp. 33-60.

Droste-Franke, Bert (2015): Using the Systems Web Approach to gain improved transparency and quality in complex system studies as basis for betterinformed risk governance. Lessons learned from energy system analyses. In: International Journal of Performability Engineering, pp. 577-587.

Droste-Franke, Bert (2018): Instrumente in der Systemanalyse für die Realisierung einer robusten Energieversorgung. In: Michael Decker, Ralf Lindner, Stephan Lingner, Constanze Scherz and Mahshid Sotoudeh (eds.): "Grand Challenges" meistern. Der Beitrag der Technikfolgenabschätzung. BadenBaden: Nomos, pp. 331-346.
Droste-Franke, Bert; Carrier, Martin; Kaiser, Matthias; Schreurs, Miranda; Weber, Christoph; Ziesemer, Thomas (2015): Improving energy decisions. Towards better scientific policy advice for a safe and secure future energy system. Heidelberg: Springer.

Droste-Franke, Bert; Fohr, Gabriele (2017): Simulating innovation of key technologies in German energy transition. Social Simulation Conference (SSC). Dublin, Ireland, 27. 09.2017.

Fagerberg, Jan; Mowery, David; Nelson, Richard (2006): The Oxford handbook of innovation. Oxford: Oxford University Press.

Foray, Dominique (2007): Tacit and codified knowledge. In: Horst Hanusch and Andreas Pyka (eds.): Elgar Companion to Neo-Schumpeterian economics. Cheltenham: Edward Elgar.

Gilbert, Nigel (2008): Agent-based models. Los Angeles: Sage.

Gilbert, Nigel; Ahrweiler, Petra; Pyka, Andreas (2010): The SKIN (Simulating Knowledge Dynamics in Innovation Networks) model. Available online at https://github.com/InnovationNetworks/skin, last accessed on 17.02.2020.

Globisch, Joachim; Droste-Franke, Bert; Fohr, Gabriele; Wassermann, Sandra (2019): Simulation von Innovationsdynamiken im Kontext der Energiewende. In: TATuP - Journal for Technology Assessment in Theory and Practice 28 (3), pp. 34-40. DOI: 10.14512/tatup.28.3.34.

Grunwald, Armin (ed.) (1999): Rationale Technikfolgenbeurteilung. Konzeption und methodische Grundlagen. Berlin: Springer.

Grunwald, Armin; Saupe, Stephan (eds.) (1999): Ethik in der Technikgestaltung. Praktische Relevanz und Legitimation. Heidelberg: Springer.

Janich, Peter (2001): Logisch-pragmatische Propädeutik. Ein Grundkurs im philosophischen Reflektieren. Weilerswist: Velbrück Wissenschaft.

Kline, Stephen; Rosenberg, Nathan (1986): An overview of innovation. In: Ralph Landau and Nathan Rosenberg (eds.): The positive sum strategy. Washington: National Academies Press, pp. 275-306.

Schilperoord, Michel; Ahrweiler, Petra (2014): Towards a prototype policy laboratory for simulating innovation networks. In: Nigel Gilbert, Petra Ahrweiler and Andreas Pyka (eds.): Simulating knowledge dynamics in innovation networks. Heidelberg: Springer, pp. 185-198.

Schumpeter, Joseph (1993): Kapitalismus, Sozialismus und Demokratie. Tübingen: A. Francke Verlag.

Schumpeter, Joseph (1912): The theory of economic development. Oxford: Oxford University Press.

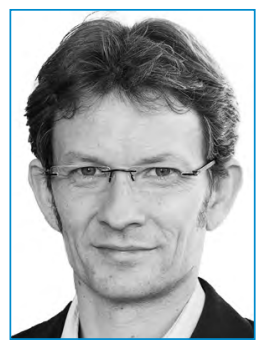

\section{DR. BERT DROSTE-FRANKE}

is head of research at IQIB. His research interests are system analyses, innovation analyses and technology assessment for policy advice, based on theoretical work, inter- and trans-disciplinary expert groups, quantitative analyses and modelling. 